\title{
Don Quijote en el jazz francés
}

\author{
Hans Christian Hagedorn \\ Universidad de Castilla-La Mancha \\ christian.hagedorn@uclm.es \\ ORCID: 0000-0001-7933-2347
}

\section{Resumen}

La intensa recepción que el Quijote ha tenido en la música francesa es un fenómeno bien conocido, documentado e investigado. Sin embargo, la crítica se ha centrado sobre todo en la música clásica y la ópera; pocos estudios se han dedicado a la música pop, el rock y el folk, y ninguno se ha ocupado hasta ahora de las huellas que la novela cervantina ha dejado en el jazz francés. En el presente artículo se documentan, se analizan y se comparan veinte ejemplos de composiciones del jazz galo que están inspiradas en la obra maestra de Cervantes, teniendo en cuenta aspectos como su recepción en el jazz de otros países, o la interesante presencia del mito de Don Quijote en el jazz francés del siglo XXI.

Palabras clave: Don Quijote, Música, Jazz francés, Recepción musical, Influencia.

\section{Résumé}

L'intense accueil que Don Quichotte a reçu dans la musique française est un phénomène bien connu, documenté et étudié. Cependant, la critique s'est concentrée principalement sur la musique classique et l'opéra; peu d'études ont été consacrées à la musique pop, au rock et au folk, et jusqu'à présent aucune n'a traité des traces que le roman cervantin a laissées dans le jazz français. Dans cet article, nous documentons, analysons et comparons vingt exemples de compositions de jazz français inspirées du chef-d'œuvre de Cervantès, en prenant en compte des aspects tels que leur réception dans le jazz d'autres pays, ou la présence intéressante du mythe de Don Quichotte dans le jazz français du 21e siècle.

Mots clé : Don Quichotte, Musique, Jazz français, Réception dans la musique, Influence.

\begin{abstract}
The intense reception that Don Quixote has had in French music is a well-known, well-documented and well-researched phenomenon. However, criticism has focused primarily on classical music and opera; few studies have been devoted to pop music, rock or folk, and none has so far dealt with the traces that the Cervantine novel has left in French jazz. In this paper we document, analyse and compare twenty examples of French jazz compositions that are inspired by the masterpiece of Cervantes, taking into account as-
\end{abstract}

\footnotetext{
* Artículo recibido el 5/03/2020, aceptado el 19/04/2020.
} 
pects such as its reception in jazz from other countries, or the interesting presence of the myth of Don Quixote in French jazz of the 21st century.

Key words: Don Quixote, Music, French jazz, Reception in music, Influence.

\section{Introducción}

La recepción del Quijote a lo largo de los últimos cuatrocientos años ha sido especialmente intensa e interesante en el caso de Francia, no solo en la literatura sino también en muchos otros ámbitos culturales, y especialmente en la música. Buena prueba de la importante huella que la obra maestra de Cervantes ha dejado en la cultura gala son, por ejemplo, las numerosas traducciones -desde las de César Oudin (1614), François de Rosset (1618), Filleau de Saint-Martin (16771678), Jean-Pierre Claris de Florian (1777/1798) o Louis Viardot (1836-1837) hasta las de Aline Schulman (1997) y Jean Canavaggio, Claude Allaigre y Michel Moner (2001)-; novelas que se caracterizan por una clara influencia quijotesca, como Le Rouge et le Noir (1830) y La Chartreuse de Parme (1839) de Stendhal, Madame Bovary (1857) de Gustave Flaubert, o Tartarin de Tarascon (1872) de Alphonse Daudet; obras de teatro como Don Quichotte (1864) de Victorien Sardou, el drama homónimo (1905) de Jean Richepin, o Dulcinée (1938) de Gaston Baty; pinturas e ilustraciones -valga aquí citar como ejemplos las de Charles Antoine Coypel (1715-1727, 1731-1734, 1751), Honoré Fragonard (1780), Gustave Doré (1863), Honoré Daumier (ca. 1864-1868), Camille Corot (ca. 1868), Paul Cézanne (ca. 1875), Jules David (1888), Henri de Toulouse-Lautrec (1897) y André Masson (1934-1936)-; adaptaciones al cómic -por ejemplo, Don Quichotte (1949-1950) de Jean Trubert, Don Quichotte (1951) de Auguste Liquois, y Don Quichotte dans la Manche (2004) de Stéphane Douay y Denis Leroux-; películas como Les Aventures de Don Quichotte (1903) de Ferdinand Zecca y Lucien Nonguet, Don Quichotte (1910) - un cortometraje de animación- de Émile Cohl, Don Quichotte (1913) de Camille de Morlhon, Don Quichotte (1965) de Jean-Paul Le Chanois, o Don Quichotte ou Les mésaventures d'un homme en colère (2005) de Jacques Deschamps; y las numerosas obras musicales inspiradas en la novela cervantina, como la ópera Don Quichotte (1910) de Jules Massenet, o los ciclos de canciones Don Quichotte à Dulcinée (Chanson romanesque, Chanson épique, Chanson à boire, 1932) de Maurice Ravel, y Quatre chansons de Don Quichotte (Chanson du départ, Chanson de Dulcinée, Chanson du Duc, y Chanson de la mort, 1932) de Jacques Ibert ${ }^{1}$. Por último, destacan también, en este sentido, y

\footnotetext{
${ }^{1}$ Véanse, por ejemplo, los trabajos de Moner (2004), Montero Reguera (2007) e Yllera (2008) sobre la recepción de la novela cervantina en Francia en general. Sobre determinados aspectos parciales de esta materia, se pueden consultar, entre muchos otros, los estudios de Bravo Castillo (2007: 66-79), Hartau (2007), Duée (2016) o Bautista Naranjo (2020). Acerca de la recepción del Quijote en Francia, véanse los siguientes párrafos introductorios y las notas 2 y 3 del presente
} 
entre muchos otros aspectos, los importantes estudios y reflexiones sobre el Quijote realizados por críticos, filólogos, cervantistas y pensadores franceses como Jean-Joseph-Achille Bertrand, Maurice Bardon, René Girard, Michel Foucault, Marthe Robert o Jean Canavaggio ${ }^{2}$.

El fenómeno de la recepción tan extraordinariamente rica y fecunda de la novela sobre el Caballero de la Triste Figura en territorio francés ha sido estudiado, documentado y analizado en un gran número de trabajos de investigación realizados por cervantistas, comparatistas, historiadores y críticos de la literatura y del arte, etc. ${ }^{3}$, y especialmente en el ámbito de la música disponemos de una bibliografía muy amplia, variada y de excelente calidad de estudios y publicaciones diversas sobre la materia, desde el catálogo de obras elaborado para la Gran Enciclopedia Cervantina (Sanz Manzano y Rubio Tovar, 2011: 8364-8368), o los trabajos que adoptan una perspectiva general, pero en los cuales se presta especial atención a la recepción del Quijote en la música francesa (Espinós, 1947: 41-61; Peyrègne, 2003; Martínez del Fresno, 2005; Padilla Alonso et al., 2016; Álvarez Calero, 2017: 86-92), hasta los estudios sobre determinados casos, aspectos y etapas de esta influencia que se encuentran, por ejemplo, en los volúmenes monográficos dirigidos por Begoña Lolo, Cervantes y el Quijote en la música. Estudios sobre la recepción de un mito (2007), Visiones del Quijote en la música del siglo $X X$ (2010) -entre otros, destacan aquí especialmente los artículos de Etcharry y Nommick- y El Quijote y la música en la construcción de la cultura europea (2018). A todo ello habría que añadir varios trabajos publicados en revistas, libros, actas de congresos, etc. (por ejemplo, Pastor Comín, 2010; Le Colleter, 2014).

Sin embargo, igual que en el caso de la recepción del Quijote en la música de otros países, la investigación acerca de las huellas de la obra maestra de Cervantes en la música francesa se ha centrado casi exclusivamente en la música clásica y la ópera. Como ha señalado Begoña Lolo (2010: 13-14), en el ámbito musicológico, gran parte de la labor investigadora realizada hasta principios del siglo XXI acerca de la relación entre la obra cervantina y la música ha estado centrada

estudio; para la música francesa, véase sobre todo, y aparte de esta introducción, el apartado 1 de este trabajo.

${ }^{2}$ Nos limitamos a señalar algunos de los ejemplos más significativos: Cervantès et le romantisme allemand (1914) de Jean-Joseph-Achille Bertrand; "Don Quichotte” en France au XVII et au XVIII ${ }^{e}$ siècle (1605-1815) (1931) y «Don Quichotte et le roman réaliste français : Stendhal, Balzac, Flaubert» (1936) de Maurice Bardon; Mensonge romantique et vérité romanesque (1961) de René Girard; Les mots et les choses. Une archéologie des sciences humaines (1966) de Michel Foucault; Roman des origines et origines du roman (1972) de Marthe Robert; y Don Quichotte : du livre au mythe. Quatre siècles d'errance (2005) de Jean Canavaggio.

${ }^{3}$ Aparte de la bibliografía mencionada en las notas 1 y 2 del presente estudio, véanse los trabajos sobre ejemplos concretos de la recepción del Quijote en Francia, incluidos en las monografías coordinadas por Hagedorn (2007: 153-182; 2009: 109-215; 2016a: 221-292). 
en enfoques históricos ${ }^{4}$; escasa atención se ha prestado, hasta la fecha, a la música popular, el rock y el folk ${ }^{5}$. Esta misma afirmación se puede hacer también en el caso del estado de la cuestión en la investigación de la recepción del Quijote en el jazz, puesto que son pocos los estudios que se han ocupado, hasta ahora, de los ecos quijotescos en este género musical ${ }^{6}$. Esta circunstancia resulta, cuando menos, llamativa, puesto que es, sin duda, bastante amplio el número de obras inspiradas en el Quijote que encontramos en muchos países, y también en Francia, en estos géneros de la música popular -pop, rock, folk, jazz- de los siglos XX y XXI. Además, como pretendemos demostrar en las páginas del presente artículo, en el caso del jazz francés destacan no solamente el número y la variedad de los ejemplos sino también el hecho de que existen varias composiciones particularmente complejas e interesantes cuyo análisis comparativo puede arrojar alguna luz sobre la importancia que ha tenido -y sigue teniendo- la recepción de la obra maestra de Cervantes en la cultura francesa en general.

Nuestro trabajo, con el que pretendemos realizar una pequeña contribución a los estudios sobre las relaciones entre la novela cervantina y la música, y sobre la recepción del Quijote en Francia, no aspira a ofrecer un inventario completo de todas las obras jazzísticas francesas en las que se hace alusión a la historia del Ingenioso Hidalgo, sino que se centra en presentar algunos ejemplos representativos de los ecos que las aventuras de Don Quijote han tenido en el jazz galo, en los siglos XX y XXI. En definitiva, nuestro análisis de la influencia de esta obra cumbre de la historia de la literatura universal en el jazz francés tiene como objetivo demostrar que se trata de un ejemplo pequeño pero a la vez significativo e ilustrativo de la historia de la recepción del Quijote en Francia en general, y en la música francesa en particular. Para ello, comenzaremos con un breve resumen de la acogida que el Quijote ha tenido en la música francesa, tanto en la música clásica y la ópera como en los diferentes géneros de la música popular, con excepción del jazz, tema en el que profundizaremos en otro apartado de este artículo. Con el fin de completar la descripción del contexto en el que se sitúa nuestro trabajo, dedicaremos un breve apartado al resumen de la recepción que la obra maestra de Cervantes ha tenido en el jazz internacional. En el apartado más extenso de este trabajo presentaremos -sin pretensión de exhaustividad- los ejemplos más destacados de las composiciones inspiradas en el Quijote que se encuentran en el jazz

\footnotetext{
${ }^{4}$ Entre los trabajos dedicados a la recepción del Quijote en la música en general destacan, por ejemplo -y aparte de los citados en las páginas anteriores del presente artículo-, los de Espinós (1947), Querol Gavalda (1948/2005), Flynn (1984), Esquival-Heinemann (1993), Denimal (2004), López Navia (2005), Lolo (2006), Adam-Schmidmeier (2007) y Ortiz-de-Urbina Sobrino (2019), así como el volumen colectivo El "Quijote” y la música de VV.AA. (2005).

${ }^{5}$ Entre los pocos estudios sobre la recepción de la novela cervantina en la música popular de los siglos XX y XXI, cabe mencionar los de Hess (2007), Labrador López de Azcona (2010), López Navia (2010, 2016 y 2018), Pujante Cascales (2010), Hess (2011) y Giorgini (2015).

${ }^{6}$ Véanse nuestros trabajos anteriores sobre esta materia (Hagedorn, 2016b, 2016c, 2018, 2019a, 2019b). Para otras publicaciones nuestras acerca del mismo tema, y que actualmente están en prensa, véase la bibliografía al final del presente estudio.
} 
francés; la descripción detallada y el análisis comparativo de estas obras se completarán con datos muy diversos, como son los compositores, los músicos, la instrumentación, el estilo, etcétera. Tras las conclusiones de nuestra investigación ofrecemos, como apéndice, un listado de ejemplos que permitirá al lector interesado una orientación muy rápida sobre las obras tratadas, compositores, títulos de álbumes y fechas de publicación (tabla $\mathrm{n}^{\circ} 1$ ).

\section{Don Quijote en la música clásica y la música popular en Francia}

La recepción de Don Quijote en la música ha sido extraordinariamente intensa y fecunda, desde el siglo XVII hasta la actualidad, en todo el mundo y en todos los géneros y estilos; de hecho, resulta casi abrumadora la riqueza de obras musicales inspiradas en esta novela, en algún personaje o alguna aventura de la misma. En la música clásica y la ópera encontramos obras de compositores como, por ejemplo, Henry Purcell (The Comical History of Don Quixote, 1695), Georg Philipp Telemann (por ejemplo, Bourlesque de Quixotte, 1720-1730; o Don Quixotte, der Löwenritter, 1761) ${ }^{7}$, Felix Mendelssohn Bartoldy (Die Hochzeit des Camacho, 1827), Richard Strauss (Don Quixote, 1897), Jesús Guridi (Una aventura de Don Quijote, 1916) o Manuel de Falla (El retablo de Maese Pedro, 1923). Por otra parte, en la música popular moderna destacan composiciones de artistas o grupos como, por ejemplo, Gordon Lightfoot (Don Quixote, 1972), Julio Iglesias (Quijote, 1982), Nik Kershaw (Don Quixote, 1984), Mägo de Oz (La leyenda de la Mancha, 1998) ${ }^{8}$, Red Hot Chili Peppers (Quixoticelixer, 1999/2006) o Coldplay (Don Quixote, 2010), por mencionar tan solo unos pocos casos especialmente conocidos (Hagedorn, 2016b: 549-553).

Como hemos señalado al principio del presente trabajo, la historia de la música clásica y la ópera francesas atesora igualmente una gran riqueza de obras inspiradas en el Quijote, por ejemplo: el Ballet de Don Quichotte dansé par Mme. Sautenir (3 de febrero de 1614), los ballets L'Entrée en France de Don Quichot de la Manche (1616/1625) y Mascarade de Don Quichotte (1700), la cantata Don Quixotte (1710) de Jean-Baptiste Morin; el ballet Les folies de Cardenio (1720) de Michel-Richard Delalande; la ópera cómica Sancho Pança gouverneur, o La Bagatelle (1727) de Jean-Claude Gillier; la cantata Don Quixotte (1728) de Philippe Courbois; el ballet cómico Don Quixotte chez la Duchesse (1743) de Joseph Bodin de Boismortier; la ópera bufa Sancho Pança Gouverneur dans l'isle de Barataria (1762) de François André Danican Philidor; la opereta Le nouveau Don Quichotte (1789) de Stanislas Champein; el ballet Don Quixotte ou Les Noces de Gamache (1822) de Federico Marco Antonio Venua; la ópera cómica Don Quixotte et Sancho Pança (1848) de Hervé Ronger; la ópera Don Quichotte

\footnotetext{
${ }^{7}$ La ópera de 1761 es conocida también bajo el título Don Quichotte auf der Hochzeit des Camacho.

8 Del grupo español de rock duro Mägo de $\mathrm{Oz}$ se conocen además al menos otras dos composiciones relacionadas con el Quijote: Siempre (Adiós Dulcinea, Pt. 2) en el álbum Gaia III: Atlantia (2010), y Adiós Dulcinea en el álbum Gaia: Epílogo (2010).
} 
(1869) de Ernest Boulanger; la ópera Don Quichotte (1869) de Émile Pessard; la ópera bouffe titulada Le gouvernement de Sancho Pança (1903) de Isidore Edouard Legouix; la ópera Don Quichotte (1910) de Jules Massenet; el oratorio Don Quichotte (1924) de Charles Tournemire; la Ouverture pour un Don Quichotte (1929) de Jean Rivier; el ciclo de canciones Don Quichotte à Dulcinée (Chanson romanesque, Chanson épique, Chanson à boire, 1932) de Maurice Ravel; el ciclo Quatre chansons de Don Quichotte (Chanson du départ, Chanson de Dulcinée, Chanson du Duc, y Chanson de la mort, 1932) de Jacques Ibert; la opereta Don Quichotte de la Manche (1934) de Ernest Weiller; el poema sinfónico Don Quichotte contre les moulins à vent (1967) de Yves Prin; o la composición para violonchelo y guitarra Don Quijote y Dulcinea (2002) de Erik Marchelie ${ }^{9}$.

En la Francia de los siglos XX y XXI, Don Quijote, sus aventuras y los demás personajes de la novela cervantina inspiraron muchas composiciones también en el ámbito de la música pop, rock y folk, la mayoría en el subgénero de la chanson, aunque también en otros estilos, por ejemplo: Don Quichotte (1958) de Jean-Claude Pascal (chanson, sencillo: Don Quichotte - Julie - Pour qui veille étoile - Devinez); Don Quichotte et Sancho Pança (1960) de Pierre Perret (chanson, álbum: Pierre Perret [Joséphine]); Le rêve de Sancho (Don Quichotte ou artiste) (1985) de Charlélie Couture (rock, pop, chanson, álbum: Art \& Scalp); Don Quichotte (No estan aquí) (1984) del grupo Magazine 60 (new wave, pop, álbum: Costa del Sol, 1985); Les moulins à vent (1998) de Johnny Hallyday (rock, pop, álbum: Ce que je sais) ${ }^{10}$; Don Quichotte is not dead (2001) de la banda Babylon Circus (rock, reggae, ska, pop, álbum: Au marché des illusions); Don Quichotte (2002) de Olivier Deck (chanson, pop, álbum: Orx); Chevalier errant (2009) del grupo Basanés 75 (rock, punk, heavy, álbum: Je me souviens); Canal St Martin (2009) del grupo Les Fatals Picards (pop, folk, chanson, álbum: Le sens de la gravité) ${ }^{11}$; Don Quichotte et les éoliennes (2011) de Philippe Crab (chanson, pop, álbum: Bestiaire); Contre vents et moulins (2012) del rapero, compositor y productor Donkichoc (hip hop, álbum: Contre vents et moulins); Don Quichotte (2014) del grupo Rout'86 (pop, rock, chanson, álbum: L'échappée); Don Quichotte (2017) de la banda Barizone Comedia Orchestra (pop, rock, álbum: Barizone

\footnotetext{
${ }^{9}$ En relación a la recepción del Quijote en la música clásica y la ópera en Francia, véanse las referencias bibliográficas incluidas en la introducción del presente estudio.

${ }^{10}$ En esta canción de Johnny Hallyday, la alusión al Quijote se encuentra en el estribillo: «Si je te dis plus rien / Dis-le moi / Si je suis plus quelqu'un que t'attends / Mais ne me dis pas que je me bats / Oh, que je me bats / Contre des moulins à vent» [consulta en línea: https://www.paroles.net/johnny-hallyday/paroles-les-moulins-a-vent].

${ }^{11}$ Véase el estribillo de esta canción de Les Fatals Picards: «Moi j’aimerais bien pouvoir me battre / en Espagne contre des moulins; / pourvu que je sois Don Quichotte, / pourvu qu'il y ait des moulins / sous un soleil qui vaut de l'or / avec la mer qui campe au loin / poussant ses vagues au creux d'un port / très loin du Canal Saint-Martin» [consulta en línea: https://www.paroles.net/fatalspicards/paroles-canal-saint-martin].
} 
Comedia Orchestra); o Ma Dulcinée (2017) de la cantante y compositora Pauline Paris (chanson, pop, álbum: Carrousel) ${ }^{12}$.

En el presente trabajo nos centramos sobre todo, y salvo alguna excepción, en música compuesta y grabada en Francia, por compositores y músicos franceses, razón por la cual no profundizaremos aquí en ejemplos de otros países francófonos como Bélgica o Canadá. Sin embargo, en el caso de Bélgica habría que mencionar a Jacques Brel, con su adaptación del musical Man of La Mancha (1965) de Mitch Leigh, Joe Darion y Dale Wasserman -en francés, L'Homme de la Mancha (1968)-, así como la canción Don Quichotte (1969) de la cantante Andrée Simons (pop, folk, chanson, álbum: Volume 1) y la pieza Quixotism (1994) de la formación Blue Alphabet (pop, rock, electronic, trance, álbum/CD maxisingle: Cybertrance). En el caso del Canadá francófono, cabría destacar el tema Le retour de Don Quichotte (1979) de Michel Rivard (pop, folk, chanson, álbum: De Longueuil à Berlin).

\section{La presencia de Don Quijote en el jazz internacional}

Un buen ejemplo de la intensa recepción que la obra maestra de Cervantes ha tenido, y sigue teniendo, en la música moderna y contemporánea es la profunda influencia que se puede observar en el ámbito del jazz internacional ${ }^{13}$. Igual que sucede en otros géneros musicales, también en el jazz encontramos una enorme riqueza y variedad de obras basadas o inspiradas en el Quijote en general, en los personajes de la novela -Don Quijote, Dulcinea, Sancho Panza (Hagedorn, 2016b, 2016c, 2018)-, o en alguno de los episodios de la misma. En este sentido, cabe destacar que la aventura de los molinos de viento (Cervantes, 1998: I/cap. VIII) es una de las escenas que más interés han despertado por parte de los compositores y los músicos del jazz ${ }^{14}$. De todos modos, y como hemos señalado anteriormente en el presente trabajo, hay que destacar que hasta ahora son muy pocos los estudios que se han realizado sobre este tema.

Entre las obras del jazz internacional -y de subgéneros como el jazz-rock o el smooth jazz, etc.- que guardan alguna relación con la novela cervantina figuran

\footnotetext{
${ }^{12}$ Otro ejemplo interesante es la pieza titulada La parade de Sancho Paca del dúo Pikpus; esta composición, una mezcla de rock experimental y de vanguardia, música electrónica e indie, fue grabada hacia finales de los años noventa y reeditada en 2018 en el álbum Pikpus Stomac.

${ }^{13}$ En el marco del presente estudio no podemos profundizar en la definición del género musical del jazz. En cualquier caso, partimos de la base de que el jazz -desde su vertiente más popular hasta la música culta o seria- es fruto del encuentro entre la música afro-norteamericana y la tradición musical europea; según el crítico alemán Joachim-Ernst Berendt, «[e]l jazz es una forma de arte musical que se originó en los Estados Unidos mediante la confrontación de los negros con la música europea. La instrumentación, melodía y armonía del jazz se derivan principalmente de la tradición musical de Occidente. El ritmo, el fraseo y la producción de sonido, y los elementos de armonía de blues se derivan de la música africana y del concepto musical de los afroamericanos» (Berendt, 1994: 695). Elementos esenciales del jazz son, por ejemplo, el blues y el swing, y el énfasis en la improvisación y la experimentación. Véase también Berendt y Huesmann (2014: 843851).

${ }^{14}$ Véase Hans Christian Hagedorn: «Los molinos de viento del Quijote en el jazz» (en prensa).
} 
obras de compositores, músicos y grupos muy diversos, por ejemplo: Barataria (1925) de Albert Brunies \& His Halfway House Orchestra (sencillo/78 rpm: Pussy Cat Rag - Barataria); Don Quijote (1927) de Eleuterio Yribarren y su grupo Red Hot Panamerican Jazz (sencillo/78 rpm: Don Quijote - Reina Mora); Sancho Panza (1953) de Sonny Stitt y Johnny Richards (álbum [EP]: Sonny Stitt Playing Arrangements from the Pen of Johnny Richards); Sancho (1964) de Pucho Escalante y el Noneto Cubano de Jazz (álbum: Jazz Cuba); Sketches for Don Quichotte (1967) de Krzysztof Komeda (álbum: Meine süsse europäische Heimat - Dichtung und Jazz aus Polen) ${ }^{15}$; Don Quijote de barba y gabán (1972) del grupo argentino Alma y Vida (álbum: Alma y Vida Vol. 2); Don Quixote (1973) de Luiz Bonfá (álbum: Jacaranda); Don Quixote's Masquerade (1975) del grupo británico IF (álbum: Tea Break Over - Back On Your 'Eads); Reflections on Don Quixote (1979) del grupo estadounidense Caldera (álbum: Dreamer); Don Quixote (1981) de Egberto Gismonti y Geraldo E. Carneiro (álbum: Em Familia); Adieu Quichotte (1984) de Hans-Joachim Roedelius (álbum: Geschenk des Augenblicks - Gift of the Moment); Don Quixote (1986) de Cesar Camargo Mariano y Milton Nascimento (álbum: Ponte das estrelas) ${ }^{16}$; Rocinante (1987) de Peter Moffitt (álbum: Zoe's Song); Don Quijote (1995) de Leif Wennerström (álbum: Don Quijote); Brother Quixote (1996) de David Lanz (álbum: Sacred Road); Quixotic (2000) de Michel Wintsch (álbum: Sharing the Thirst); Sanchopanza (2002) y Dulcinea (2003) del grupo italiano Actis Band (en los álbumes Don Quijote y Garibaldi, respectivamente); Quixotic (2003) de Florian Trübsbach (álbum: $M a$ son \& Dixon); Sancho (2004) del grupo suizo Stimmhorn \& Kold Electronics (álbum: Igloo); The long ride of Sancho Panza (2005) del dúo austríaco-alemán Los Glissandinos (álbum: Stand Clear); Quixotism (2005) de Larry Martus (álbum: Transcendence); Dulcinea (2007) del proyecto estadounidense Abstract Audio Systems (álbum: Poems for Innogen); Don Quixote (2007) de Tom Wright (álbum: Destination); Quixotic (2008) de The Stein Brothers Quintet (álbum: Quixotic); Quixotic (2009) de Ivo Neame (álbum: Caught in the Light of Day); Rosinante (2012) del grupo finlandés Rakka (álbum: Soutu); Dulcinea (2012) de Jasper van't Hof (álbum: Euvre); Don Quixote's Final Quest (2014) de Peter White (álbum: Smile); Knight Errant (2014) del Paul Edis Sextet (álbum: Mr Hipster); Quixotic (2015) del grupo estadounidense Hypercolor (álbum: Hypercolor); o Quixote (2018) de Christian Artmann (álbum: Our story), entre muchos otros. Hay también algunas suites de jazz basadas en el Quijote, por ejemplo: Windmill

\footnotetext{
15 Sketches for Don Quichotte es un tema instrumental; sin embargo, en la versión abreviada (de apenas dos minutos y medio) incluida en el álbum Meine süsse europäische Heimat, esta composición de Krzysztof Komeda sirve de música de fondo para la recitación de la traducción alemana del poema Don Kichot - Ritterballade, de Stanisław Grochowiak (1934-1976). Hay otra versión mucho más extensa (de más de 11 minutos) y completamente instrumental, grabada igualmente en 1967; esta versión, titulada simplemente Don Kichot, está disponible en la reedición del álbum en CD, publicado en 2012 por el sello polaco Anex (Polish Jazz Masters).

${ }^{16}$ Este tema instrumental alcanzó gran popularidad en la versión (con letra en portugués) del cantante, compositor y guitarrista brasileño Milton Nascimento (incluida en el álbum Miltons, 1989).
} 
Tilter: The Story of Don Quixote (1969) de Kenny Wheeler; A Song of Don Quixote (1981) de Mitsuaki Kanno; Don Quijote (2004) de Roberto Nannetti; Chivalrous Misdemeanors (2005) de Ron Westray; y Adventures of a Quixotic Character (2014) de Tom Harrell ${ }^{17}$.

\section{La presencia de Don Quijote en el jazz francés}

\subsection{Primeros contactos entre el Quijote y el jazz en Francia: Jean Rivier, Mi- chel Legrand, Jean Schwarz}

En la música francesa, la primera composición inspirada en el Quijote en la que encontramos alguna influencia del jazz es una obra del ámbito de la música clásica moderna que ya hemos mencionado antes en el presente estudio; se trata de la Ouverture pour un Don Quichotte (1929) de Jean Rivier. Según Sanz Manzano y Rubio Tovar (2011: 8368), el compositor francés realiza en esta pieza «una peculiar adaptación de El Quijote a la música empleando ritmos tan ajenos y extemporáneos a la obra como el jazz». Sin embargo, no hemos podido encontrar ninguna grabación de esta obra ${ }^{18}$.

Otro ejemplo de una composición francesa que alude -indirectamente- al héroe cervantino y que tiene rasgos jazzísticos es la canción The Windmills of Your Mind (Les moulins de mon cour, 1968) de Michel Legrand ${ }^{19}$. Este célebre

\footnotetext{
${ }^{17}$ Para más información sobre estos y otros ejemplos véase Hagedorn (2016b, 2016c, 2018, 2019a y 2019b). En relación con las suites de jazz basadas en el Quijote, véase especialmente Hagedorn (2016c). Las suites de Kenny Wheeler, Mitsuaki Kanno y Roberto Nannetti se publicaron en sendos álbumes homónimos (en vinilo y/o CD). La suite Chivalrous Misdemeanors de Ron Westray permanece inédita; en su estreno, los días 5-7 de mayo de 2005, en el Lincoln Center de Nueva York (Jazz at Lincoln Center, Frederick P. Rose Hall), la obra fue interpretada por la Jazz at Lincoln Center Orchestra (con la participación de Wynton Marsalis, Ron Westray, Sean Jones, Marcus Printup, Ted Nash, Joe Temperley, Xavier Davis, Carlos Henriquez, Jonathan Blake, los cantantes Sachal Vasandani y Jennifer Sanon, y el actor británico Patrick Tull, entre otros). La única grabación existente es la del tercer día de estreno, el 7 de mayo de 2005; sin embargo, esta grabación nunca fue publicada. La New York Public Library for the Performing Arts (Lincoln Center, Rodgers and Hammerstein Archives of Recorded Sound) conserva una copia de esta grabación (Research Collections, Recorded Sound, call number LDC 44249 [CD]); esta es, a nivel mundial, la única copia conservada y accesible al público, en una biblioteca o un archivo. Por último, la suite Adventures of a Quixotic Character de Tom Harrell se publicó en el álbum titulado Trip (2014).

${ }^{18}$ La partitura de la Ouverture pour Don Quichotte de Jean Rivier fue publicada en París, en 1930, por la editorial Salabert.

${ }^{19}$ Michel Legrand compuso la música de este tema; la letra de la versión inglesa es obra de Alan Bergman y Marilyn Bergman, el autor de la letra de la versión en francés es Eddy Marnay. Legrand (1932-2019) es conocido como compositor en el ámbito del cine; sus trabajos forman parte de las bandas sonoras de películas como Les parapluies de Cherbourg (1964), The Thomas Crown Affair (1968, 1999), Atlantic City (1980), Yentl (1983), Never Say Never Again (1983), o Prêt-àPorter (1994), entre otras. Grabó también varios álbumes de jazz, y colaboró -como compositor, director, arreglista o pianista- con otros músicos de este género musical, como Miles Davis, John Coltrane, Bill Evans, Ben Webster, Hank Jones, Art Farmer, Gerry Mulligan, Phil Woods, o Stéphane Grappelli. Véanse las observaciones sobre el álbum Legrand Jazz (1958), en Morton y Cook (2011: 224).
} 
tema, una chanson romántica con cierto aire de balada de jazz - sin duda, la composición más conocida de Legrand-, fue utilizado en la película estadounidense The Thomas Crown Affair (1968), y también en el remake de $1999^{20}$. En la versión original, la canción, con la letra en inglés, fue interpretada por el cantante británico Noel Harrison -en 1969, esta versión (que tiene una duración de 02:21 minutos) recibió en Hollywood el Oscar a la mejor canción original-; el remake contaba con la interpretación del músico británico Sting, que recuerda al estilo de los standards del jazz. Existen muchas otras versiones, tanto vocales como instrumentales, en la música pop y en el jazz ${ }^{21}$. Como dato curioso, resulta especialmente llamativo el hecho de que el compositor galo se inspirara, para los primeros compases de la canción, en el Andante de la Sinfonía concertante para violín, viola y orquesta en mi bemol mayor (1779, K364), de Wolfgang Amadeus Mozart ${ }^{22}$. La relación entre The Windmills of Your Mind y la novela cervantina es ciertamente superficial y, en cualquier caso, indirecta, puesto que en la letra de la canción -tanto en su versión inglesa ${ }^{23}$, que es la que alcanzó mayor popularidad a

${ }^{20}$ La película The Thomas Crown Affair (1968) fue dirigida por Norman Jewison, con un reparto en el que destacaban Steve McQueen y Faye Dunaway. El remake, rodado en 1999 con actores como Pierce Brosnan, Rene Russo, Faye Dunaway, Ben Gazzara y Esther Cañadas, fue obra del director John McTiernan.

${ }^{21}$ Aparte de las interpretaciones de Noel Harrison, Sting, y el propio Michel Legrand, destacan las de Dusty Springfield (1969), Petula Clark (1969), José Feliciano (1969), Vanilla Fudge (1969), Billy Paul (1973), Herman van Veen (1973), Mireille Mathieu (1973), Sylvie Vartan (1974), Swing Out Sister (1989), Kiri Te Kanawa (1992), Udo Lindenberg (1997), Neil Diamond (1998), Alison Moyet (2004), Dianne Reeves (2008), Barbra Streisand (2011) y Eva Mendes (2011). En clave de jazz, podríamos mencionar, por ejemplo, las versiones de George Benson (1968, instrumental), Henry Mancini (1969, instrumental), Michel Legrand (1969), Oscar Peterson (1970, instrumental), Dizzy Gillespie (1970, instrumental), James Last (1970, instrumental), Toots Thielemans (1990, instrumental; 1998, con Johnny Mathis), Art Farmer (1993, instrumental), Sting (1999), Abbey Lincoln (2000), Paul Motian (2011), Sinne Eeg (2012), David Sanborn y Randy Crawford (2015), así como Paolo Fresu, Richard Galliano y Jan Lundgren (2019, instrumental). En 2012 se publicó (en CD) un recopilatorio de diversas interpretaciones de esta canción, con el título Windmills of Your Mind (20 versions).

22 Véanse, por ejemplo, los artículos sobre Michel Legrand y The Windmills of Your Mind en la Wikipedia (versiones en francés, inglés, español y alemán), donde se encuentra información general, pero útil, sobre esta canción. Para más detalles véanse, entre otros, los trabajos de Bennett (2014) y Keiper (2016: 27-43).

${ }^{23}$ Como hemos señalado más arriba, la letra de la versión inglesa es obra de Alan y Marilyn Bergman: «Round, like a circle in a spiral, like a wheel within a wheel, / Never ending or beginning on an ever-spinning reel, / Like a snowball down a mountain or a carnival balloon, / Like a carousel that's turning, running rings around the moon, / Like a clock whose hands are sweeping past the minutes of its face, / And the world is like an apple whirling silently in space, / Like the circles that you find in the windmills of your mind. // Like a tunnel that you follow to a tunnel of its own, / Down a hollow to a cavern where the sun has never shone, Like a door that keeps revolving in a half-forgotten dream, / Or the ripples from a pebble someone tosses in a stream, / Like a clock whose hands are sweeping past the minutes of its face, / And the world is like an apple whirling silently in space / Like the circles that you find in the windmills of your mind. // Keys that jingle in your pocket, words that jangle in your head, / Why did summer go so quickly? Was it 
nivel mundial, como en la francesa ${ }^{24}$ - no se mencionan la novela ni sus personajes. Sin embargo, los paralelismos a nivel temático, junto con el empleo del motivo de los molinos de viento -que se recrea también musicalmente, mediante el empleo de estructuras y formas circulares que imitan el movimiento de las aspas-, evocan de manera bastante clara las aventuras y los sentimientos amorosos del Caballero de la Triste Figura: la alusión metafórica a los molinos de viento sirve para ilustrar los temas centrales de la canción, a saber, la imposibilidad de luchar contra los recuerdos recurrentes de un amor perdido; la confusión o incluso la locura en el sentimiento amoroso en general; el amor y la soledad; y la fugacidad del tiempo. La voz poética de la letra de la canción parece pertenecer a un personaje quijotesco, que lucha inútilmente contra los recuerdos, la nostalgia, la tristeza, la sensación de pérdida, y el inexorable paso del tiempo. En definitiva, The Windmills of Your Mind puede ser considerada una composición romántica de música pop -y de la tradición francesa de la chanson- con cierta influencia del jazz, y que juega con la alusión a una de las aventuras más conocidas del personaje cervantino ${ }^{25}$.

something that you said? / Lovers walk along a shore and leave their footprints in the sand, / Is the sound of distant drumming just the fingers of your hand? / Pictures hanging in a hallway or the fragment of a song, / Half-remembered names and faces but to whom do they belong? / When you knew that it was over you were suddenly aware, / That the autumn leaves were turning to the colour of her hair. // A circle in a spiral, a wheel within a wheel, / Never ending or beginning, on an ever-spinning reel, / As the images unwind, like the circles that you find, / In the windmills of your mind» [consulta en línea: http://www.thewindmillsofyourmind.com/thewindmillsofyourmind].

${ }^{24}$ La letra de la versión francesa es obra de Eddy Marnay: «Comme une pierre que l'on jette / Dans l'eau vive d'un ruisseau / Et qui laisse derrière elle / Des milliers de ronds dans l'eau / Comme un manège de lune / Avec ses chevaux d'étoiles / Comme un anneau de Saturne / Un ballon de carnaval / Comme le chemin de ronde / Que font sans cesse les heures / Le voyage autour du monde / D'un tournesol dans sa fleur / Tu fais tourner de ton nom / Tous les moulins de mon cœur. // Comme un écheveau de laine / Entre les mains d'un enfant / Ou les mots d'une rengaine / Pris dans les harpes du vent / Comme un tourbillon de neige / Comme un vol de goélands / Sur des forêts de Norvège / Sur des moutons d'océan / Comme le chemin de ronde / Que font sans cesse les heures / Le voyage autour du monde / D'un tournesol dans sa fleur / Tu fais tourner de ton nom / Tous les moulins de mon cœur. // Ce jour-là près de la source / Dieu sait ce que tu m'as dit / Mais l'été finit sa course / L'oiseau tomba de son nid / Et voilà que sur le sable / Nos pas s'effacent déjà / Et je suis seul à la table / Qui résonne sous mes doigts / Comme un tambourin qui pleure / Sous les gouttes de la pluie / Comme les chansons qui meurent / Aussitôt qu'on les oublie / Et les feuilles de l'automne / Rencontre des ciels moins bleus / Et ton absence leur donne / La couleur de tes cheveux. // Une pierre que l'on jette / Dans l'eau vive d'un ruisseau / Et qui laisse derrière elle / Des milliers de ronds dans l'eau / Au vent des quatre saisons / Tu fais tourner de ton nom / Tous les moulins de mon cœur» [consulta en línea: https://www.parolesmusique.com/eng/Michel_Legrand-Les_Moulins_De_Mon_Coeur-lyrics,p88963].

${ }^{25}$ El profundo interés que Michel Legrand sentía por el Quijote, y su buen conocimiento de la obra, se reflejan también en el hecho de que en 1972 compuso una suite inspirada en la novela cervantina, para la película The adventures of Don Quixote (Les aventures de Don Quichotte), una adaptación para la televisión realizada por el director canadiense Alvin Rakoff (en el reparto destacaban actores como Rex Harrison, Frank Finlay, Rosemary Leach, Robert Eddison y Bernard Hepton). La suite quijotesca de Legrand se reeditó en varias ocasiones, por ejemplo en 2005 y 
Un caso similar - de una obra musical francesa inspirada en el Quijote, y que incorpora elementos del jazz, aunque no se puede clasificar como composición de este género- es la suite Don Quichotte de Jean Schwarz ${ }^{26}$, una obra que fue creada y grabada entre 1975 y 1976, aunque el disco no se publicaría hasta 1981. Se trata de una composición que pertenece al ámbito de la música electroacústica -o música concreta (Etcharry, 2017a: 10384)-, aunque juega también con influencias y elementos de otros géneros como, por ejemplo, la música clásica y el jazz experimental y de vanguardia ${ }^{27}$. En la grabación del álbum participaron el propio Jean Schwarz (instrumentos electrónicos, sintetizadores, magnetófono) y una orquesta de cuerdas, con músicos e instrumentos sin especificar, dirigida por Guy Reibel. Don Quichotte es una suite que consta de cinco movimientos: Prologue, Moulins à vent, Devise avec Sancho, Dulcinée du Toboso, y Combat, maladie et mort $^{28}$. La duración de la obra es de 44:20 minutos. Como explica el compositor en el texto incluido en la contraportada del disco, los diferentes movimientos de la suite evocan «quelques aspects de la vie quotidienne d'un Don Quichotte contemporain» (Schwarz, 1981). En el mismo lugar, Schwarz ofrece también unos breves comentarios sobre cada uno de estos cinco temas; sobre la primera pieza, titulada Prologue, el compositor hace la siguiente observación: «Un long préam-

2012. Acerca de la canción The Windmills of Your Mind, véase también Hagedorn (2016a: 558560), así como, del mismo autor, el estudio «Los molinos de viento del Quijote en el jazz» (en prensa).

${ }^{26}$ Jean Schwarz nació en Lille (Francia) en 1939; fue miembro del prestigioso e innovador Groupe de Recherches Musicales en París, profesor del Conservatorio de Gennevilliers, y es autor de álbumes electroacústicos y experimentales como Anticycle II (1974), Erda / Symphonie (1978), Year of the Horse / L'Enfance de Vladimir Kobalt (1980), Gamma Plus / Suite N (1983), Quatre Vingts (1995), o Dilin Dalan (2000). Varias de sus creaciones están inspiradas en obras literarias, por ejemplo, L'Odyssée de Kazantzaki (2004), basada en la obra de Nikos Kazantzakis. Schwarz compuso varias secuencias musicales o de efectos sonoros para películas de directores franceses, por ejemplo, Ici et ailleurs (1976) de Jean-Luc Godard, Providence (1977) de Alain Resnais, u Eaux profondes (1981) de Michel Deville.

${ }^{27}$ Véase la siguiente descripción de la suite Don Quichotte de Jean Schwarz: «This is pretty different from the other LP I posted a while back [Suite N, 1981-1982], which was mostly focused on electronic material. This is a more kaleidoscopic affair, exploring everything from field recordings, processed voice, electronic timbres and acoustic instruments, to musical passages that cover anything from contemporary classical music to jazz, free and less so, to weird psychedelic library segments, featuring highly processed instruments all throughout. It has a dreamlike quality that sometimes reminds me of Battiato's fantastic M.elle Le "Gladiator" and "Cafè - Table - Musik" from his eponymous 1977 LP» (Van Halen, 2016). Acerca de Jean Schwarz y su interés por el jazz, véase también la biografía en la página web del Centre de documentation de la musique contemporaine (Cdmc, 2014), así como la reseña de otro álbum de Jean Schwarz, Gamma Plus (Nordin, sin año).

${ }^{28}$ En su artículo sobre la suite de Jean Schwarz que se publicó en la Gran Enciclopedia Cervanti$n a$, Stéphan Etcharry hace referencia a una versión «en ocho cuadros» (Etcharry 2017a: 10384); sin embargo, el disco de vinilo que se publicó en 1981 incluye solo los cinco movimientos citados. En el texto reproducido en la contraportada del disco, el propio Schwarz se refiere a una «suite musicale en six tableaux» (Schwarz 1981). 
bule situe le héros face aux agressions du monde actuel: pollution, bruits, guerre, vulgarité, profit». En cuanto a Moulins à vent, por ejemplo, el creador francés precisa: «Une cithare modulée électroniquement dans un synthétiseur situe le combat contre les moulins à vent. La pulsion regulière est cassée par des sons électroniques». En relación con el movimiento titulado Dulcinée du Toboso, Schwarz ofrece la siguiente descripción: «Après un court voyage concret et chaotique, Don Quichotte retrouve sa "Dame'" au son des violons de l'orchestre. Leur rencontre se termine aux arènes de Pampelune». Como conclusión, el compositor señala: «Le thème de Don Quichotte m'a permis de passer d'un genre musical à un autre. Les techniques électroacoustiques m'ont aidé en ajoutant leur propre démence à la mienne» (Schwarz, 1981). Como se infiere de estos comentarios del compositor francés, la suite Don Quichotte no pretende ser una ilustración musical de la novela cervantina sino una reescritura moderna del mito, una obra que refleja en la música las vivencias de un personaje de características quijotescas, en la segunda mitad del siglo XX. Además, al establecer un vínculo entre la locura propia, la de sus medios -o técnicas- y la del personaje cervantino, Schwarz insinúa que esta obra podría entenderse también como un autorretrato musical en clave quijotesca $^{29}$.

\subsection{La presencia del Quijote en el jazz francés del siglo XX: Léon Francioli y Pierre Favre, Stéphane Grappelli, Sylvain Kassap, Claude Nougaro y Collec- tif $\mathrm{Mu}$, entre otros}

Como hemos visto en el apartado anterior del presente trabajo, entre los años veinte y los años setenta del siglo XX se producen los primeros contactos más o menos directos o indirectos, según el caso- entre el Quijote y el jazz francés o, mejor dicho, aquellos compositores franceses que incorporaban en sus obras alguna influencia jazzística. Sin embargo, es en realidad a partir de la década de los setenta cuando en el jazz francés -es decir, entre los compositores, músicos y grupos que se dedican a este género musical-comienza a surgir un interés especial y genuino por la novela cervantina y los personajes y episodios más conocidos de la misma.

En 1976, el dúo suizo integrado por el contrabajista Léon Francioli y el batería Pierre Favre graba el álbum Le bruit court..., para el sello independiente francés L'Escargot. Este disco de free jazz, jazz experimental y de vanguardia incluye un tema dedicado a la novela cervantina, titulado Le rêve de Don Quichotte. Esta pieza instrumental, que tiene una duración de 04:55 minutos, y que podría

${ }^{29}$ Otra obra de música electroacústica - o música concreta- inspirada en la novela cervantina, y creada por un compositor francés, es la pieza Don Quichotte Corporation (1981) de Alain Savouret; sin embargo, en este caso no hay influencia del jazz. 
describirse como una improvisación libre, atonal, basada en la combinación y superposición de diferentes sonidos, ruidos y efectos sonoros, crea un ambiente onírico o, incluso, fantasmagórico. Mencionamos este ejemplo en el contexto del presente trabajo ya que el disco Le bruit court... fue publicado y distribuido por un sello galo (L'Escargot), y porque ambos músicos desarrollaron gran parte de su carrera en Francia, y en colaboración con muchos músicos franceses.

Dos años más tarde, en 1978, el violinista franco-italiano Stéphane Grappelli grabó el álbum + Cordes, que incluye otro tema instrumental inspirado en Don Quijote; el título de la pieza en cuestión es Barataria, una composición de Christian Chevallier que tiene una duración de 03:58 minutos. En la grabación del disco participaron los siguientes músicos: Stéphane Grappelli (violín), Maurice Vander (piano), François Jeanneau (sintetizadores), Gérard Niobey (guitarra), Tony Bonfils (bajo), André Ceccarelli (batería), y Michel Delaporte (percusión); Christian Chevallier aparece como director de orquesta. Barataria es una balada romántica y muy melódica en la que se mezclan elementos del jazz latino y el smooth jazz con un ritmo suavemente swingueante y reminiscencias del gypsy jazz, el estilo del Quinteto del Hot Club de Francia que Grappelli había fundado junto con el guitarrista Django Reinhardt en 1934. El título de la pieza hace alusión al episodio de la Ínsula Barataria, en la segunda parte del Quijote de Cervantes (1615), cuando Sancho Panza por fin alcanza su sueño de convertirse en gobernador (Cervantes, 1998: II/caps. XXXII, XLII-LIII/889-904, 967-1067) ${ }^{30}$.

En los años ochenta del siglo XX, los ejemplos más destacados de composiciones francesas de jazz inspiradas en la novela cervantina son obra del guitarrista André Bénichou y de la cantautora y acordeonista Michèle Buirette. En el caso del primero se trata de los temas instrumentales Don Quichotte y Don Quichotte $n^{o} 2$, de su álbum Adagissimo $(1981)^{31}$. Bénichou es conocido sobre todo por sus grabaciones de música clásica para guitarra, con unos arreglos modernos, muy sencillos y melodiosos, en los que se mezclan la música pop y el smooth jazz. Sus trabajos más populares datan de los años sesenta y setenta, con títulos como Guitare Bach (1964) y Jazz Guitar Bach (1965). Tanto Don Quichotte -una pieza lenta y melancólica, con una duración de 02:21 minutos- como Don Quichotte $n^{o}$ 2 -un tema agradable con una duración de 03:52 minutos que se caracteriza por un ritmo suave y la influencia de la música pop y el jazz latino- son composiciones del propio Bénichou; ambas podrían ser definidas como una combinación de smooth jazz, jazz romántico, easy listening, y música clásica, aunque en el caso de

\footnotetext{
${ }^{30}$ En teoría, es posible que el tema compuesto por Christian Chevallier haga referencia al pequeño municipio de Barataria que se encuentra cerca de Nueva Orleans (Luisiana, Estados Unidos de América), o al pueblo con el mismo nombre en San Juan-Laventille (Trinidad y Tobago); sin embargo, hay que tener en cuenta también que ambas localidades fueron bautizadas con este nombre en homenaje al célebre episodio de la obra cervantina.

${ }^{31}$ En la grabación de este álbum participaron los siguientes músicos: André Bénichou (guitarra clásica), Raoul Duflot Verez (piano, Fender Rhodes), Tony Bonfils (bajo), Serge Eymard (guitarra acústica, guitarra fretless), Jean-Claude Oliver (sitar), Jeff Leroux (percusión), Lionel Lecreux (batería), Patrick Oliver (teclados, voz, arreglos, dirección de orquesta).
} 
la primera sería también correcto hablar de un estilo cercano a la música new age. Además, Don Quichotte está claramente inspirado en el archiconocido Adagio del Concierto de Aranjuez (1939) de Joaquín Rodrigo, por lo que se puede decir que este tema de André Bénichou hace referencia, de manera bastante directa, a la música española, y con ello, por extensión, a la cultura de la tierra de Don Quijote.

El álbum La mise en plis (1985) de la cantante, compositora y acordeonista francesa Michèle Buirette podría ser clasificado como jazz moderno, jazz experimental y jazz de vanguardia. Con excepción de los temas Le devis de l'amour y Le chevalier à la triste figure, las demás piezas en este disco -que incluye un total de siete composiciones- son instrumentales ${ }^{32}$. Le chevalier à la triste figure, compuesto por Michèle Buirette, es un tema experimental, con una duración de 06:20 minutos; la pieza fue grabada por Michèle Buirette (acordeón), Didier Petit (violonchelo) y Bruno Girard (violín, voz). Esta composición se caracteriza por un ritmo libre -que en algunas partes se convierte en un tango- y el juego con disonancias y, en algunos momentos, la atonalidad, así como diversas influencias que abarcan desde el jazz musette hasta el gypsy jazz o jazz manouche. Se trata de un tema melancólico, muy complejo, con muchos cambios armónicos y de ritmo, e instrumental casi en su totalidad: solo al principio hay un breve trozo de doce segundos (00:00-00:12 minutos) en el que aparece la voz de Bruno Girard recitando un breve fragmento de un poema de Raymond Queneau, un texto surrealista, aparentemente sin relación directa con el tema quijotesco ${ }^{33}$. En resumen, se puede decir que estamos ante una composición peculiar, de gran complejidad, y que crea un ambiente misterioso y un tanto fantasmagórico.

En 1990, el batería turco Okay Temiz y el saxofonista, clarinetista y compositor francés Sylvain Kassap publican el álbum Istanbul' da Eylül, un disco de

\footnotetext{
${ }^{32}$ La grabación del disco La mise en plis fue realizada por los siguientes músicos: Michèle Buirette (acordeón, voz), Didier Petit (violonchelo), Bruno Girard (violín, voz), Dominique Fonfrède (voz), Hélène Sage (voz, flauta, contrabajo), Ge Cabannes (teclados, contrabajo), Francis Gorgé (sintetizador, percusión, guitarra), Jean-Jacques Birgé (sintetizador, percusión, trombón) y Bernard Vitet (trompeta).

${ }^{33}$ El fragmento - cuyo origen y autoría no se indican en la contraportada del disco- pertenece a la obra Cent mille milliards de poèmes (1961) de Raymond Queneau (1903-1976); se trata de los siguientes cuatro versos: «Le roi de la pampa retourne sa chemise / Pour la mettre à sécher aux cornes des taureaux / Le chauffeur indigène attendait sous la pluie / Il chantait tout de même oui mais il chantait faux». En la versión original de Raymond Queneau, el tercer verso termina en las palabras «attendait dans la brise», en lugar de «attendait sous la pluie». Hay que tener en cuenta que en esta obra del surrealismo francés, unos versos se pueden combinar libremente con otros, lo cual explica también el título del libro. Deseamos expresar nuestro agradecimiento a Florence Labasque, por su ayuda en la transcripción de estos versos. Nótese que en los versos citados hay alguna palabra que puede hacer pensar en España («cornes des taureaux»), y que la pareja formada por «Le roi de la pampa» $\mathrm{y}$ «Le chauffeur indigène» recuerda a la relación entre Don Quijote y su escudero, sobre todo en el contexto de una composición titulada Le chevalier à la triste figure; de todas maneras, no estamos aquí ante una referencia intertextual, sino que se trata de un juego con asociaciones que crea, sobre todo, un efecto surrealista y de misterio.
} 
jazz moderno, free jazz y de vanguardia, que incluye el tema Quixote, compuesto por Sylvain Kassap ${ }^{34}$. El álbum, en el que se combinan algunas pistas tranquilas y melodiosas (como Mirage u On Yedi) con otras más animadas, o más complejas desde el punto de vista del ritmo y la armonía (como Çiçek Pasaji, Tecek Otlatmasi, o Karaköy), conjuga influencias de la música turca, la música oriental y el jazz contemporáneo europeo. Quixote, una pieza instrumental con una duración de 06:23 minutos, es un tema muy tranquilo y melodioso, aunque al mismo tiempo también solemne, melancólico, sutilmente romántico, sombrío y misterioso; se trata de una composición especialmente bella e interesante, sin duda una de las musicalizaciones más sobresalientes del mito literario de Don Quijote en el género del jazz, a nivel universal. Sylvain Kassap volvió a grabar este tema en 1994, con el Sylvain Kassap Quartet, para su álbum titulado, precisamente, Quixote ${ }^{35}$.

El cantante francés Claude Nougaro dedicó otro tema a la novela cervantina, titulado Don Quichotte et Sancho, que se incluyó en su álbum L'Enfant phare $(1997)^{36}$. Don Quichotte et Sancho es un tema que podría clasificarse como una combinación de música pop o rock con influencias del jazz y elementos de la tradición francesa de la chanson. La música fue compuesta por Arnaud Dunoyer de Segonzac, mientras que la letra es obra de Claude Nougaro $^{37}$. La pieza tiene una

${ }^{34}$ El disco Istanbul' da Eylül fue grabado en septiembre de 1989 en Estambul, con la participación de Okay Temiz (batería, percusión), Sylvain Kassap (saxofón soprano, saxofón sopranino, clarinetes), Lennart Åberg (saxofón tenor, saxofón soprano, flauta), Nedim Nalbantoğlu (violín), Alain Blesing (guitarras), e Yves Rousseau (contrabajo).

${ }^{35}$ El álbum Quixote del Sylvain Kassap Quartet fue grabado en 1993 (y publicado en 1994), por los siguientes músicos: Sylvain Kassap (saxofón, clarinete), Philippe Deschepper (guitarra), Marc Buronfosse (contrabajo) y David Pouradier Duteil (batería). En este disco, la versión del tema Quixote tiene una duración de 05:21 minutos.

${ }^{36}$ Este álbum fue grabado por una treintena de músicos entre los que destacan, por ejemplo, Claude Nougaro (voz), Loïc Pontieux (batería), Laurent Vernerey (bajo), Jean-Marie Ecay (guitarras), Arnaud Dunoyer de Segonzac (piano, teclados), Denis Benarrosh (percusión), Eddy Louiss (piano, órgano), Patrick Mortier (trompeta), Jef Coolen (trompeta), Pietro Lacirignola (saxofón alto), Dieter Limbourg (saxofón alto), Eddy de Vos (saxofón tenor, clarinete), Henri Ylen (saxofón tenor), Marc Godfroid (trombón), Lode Mertens (trombón), Johan Vandendriessche (flauta), José Fontaine (tuba), y Maurice Vander (piano); no especificamos aquí los músicos encargados de las secciones de violines y violoncelos (esta información está disponible en la contraportada del disco).

${ }^{37}$ La letra de la canción es muy sencilla, y bastante repetitiva: «La poésie c'est mon dada / Mon dada, mon dada / Et l'utopie c'est mon topo / Mon topo, mon topo / La poésie c'est mon dada / Et l'utopie mon topo, mon topo. // On peut me traiter de fada / De fêlé, de marteau / Ce sera toujours mon B.A.-Ba / Ma devise, mon credo / La poésie c'est mon dada / Et l'utopie mon topo, mon topo. // Don Quichotte qui chevauche sur son pâle palefroi / Et Sancho qui le suit en gardant son sangfroid / Chantent ça en duo de moulin en château / Au p'tit trot des sabots / Et soudain au galop, au galop, au galop: / La poésie c'est mon dada / Et l'utopie c'est mon topo / La poésie c'est mon dada / Et l'utopie mon topo / Chantent Don Quichotte et Sancho. // La poésie c'est mon dada / Mon drapeau, mon barda / Et l'utopie c'est mon topo / J'ai le rêve dans la peau / La poésie c'est mon dada / Et l'utopie mon topo, mon topo. // Don Quichotte qui chevauche sur son pâle palefroi / Et Sancho qui le suit en gardant son sang-froid / Chantent ça en duo pour les vaches, pour les veaux / Par les monts, par les vaux / Et encore au galop, au galop, au galop: / La poésie c'est mon dada / Et 
duración de 03:50 minutos. A pesar de los frecuentes cambios de ritmo -más característicos del jazz que de la música pop-, se trata de una canción muy pegadiza, y además, muy enérgica y alegre, cuyo tema podría sintetizarse diciendo que estamos ante un canto a la poesía y la utopía, a los sueños, la fantasía y la pasión (Etcharry, 2017b; Lolo, 2017) ${ }^{38}$.

En el mismo año en el que Claude Nougaro publicó su canción quijotesca, el grupo Collectif Mu grabó el tema instrumental Don Quichotte para su álbum homónimo (1997). Esta pieza, que tiene una duración de 08:23 minutos, fue compuesta por el guitarrista y uno de los líderes del grupo, Jean-Loup Bonneton ${ }^{39}$. Se trata de una composición de jazz contemporáneo, experimental y de vanguardia, caracterizada por jugar con disonancias y grandes espacios para la improvisación, un tema con un ritmo muy acelerado, vivaz, casi frenético, y que parece estar dedicado a la locura del protagonista de la novela cervantina. Hay que tener en cuenta, por otra parte, que hay varios elementos que sirven para estructurar la pieza y poner orden en lo que, a primera vista, se presenta como un gran caos: por ejemplo, algunas melodías o frases que se repiten, algunas secciones más tranquilas que funcionan como pausas en el delirio, o el propio ritmo, que es sin duda una de las facetas más interesantes de este homenaje jazzístico al Ingenioso Hidalgo. Resumiendo, se trata de una composición muy dinámica y de gran complejidad, que ofrece una idea de la excelente calidad del jazz francés en aquel momento y del profundo interés que los músicos galos de este género habían desarrollado a finales del siglo XX por la obra maestra de Cervantes ${ }^{40}$.

\subsection{El Quijote en el jazz francés del siglo XXI: desde L'Effet Vapeur y el Oli- vier Thémines Trio hasta Franck Tortiller y François Corneloup, entre otros}

En las primeras dos décadas del siglo XXI, el interés del jazz francés por el Quijote se intensifica de una manera muy llamativa; de hecho, en estos veinte años se pueden encontrar fácilmente tantos ejemplos como en todo el siglo anterior. Para empezar, en 2002, el grupo L'Effet Vapeur publica el tema instrumental Quichotte, como parte de su álbum en directo En concert - Je pense que... Esta

l'utopie c'est mon topo / La poésie c'est mon dada / Et l'utopie mon topo / Chantent Don Quichotte et Sancho» [consulta en línea: https://www.paroles-musique.com/eng/Claude_NougaroDon_Quichotte_Et_Sancho-lyrics,p79889].

${ }^{38}$ Claude Nougaro grabó otra versión de este tema, en su concierto en Toulouse, el 21 de julio de 1998; esta versión fue incluida en su álbum en directo Hombre et lumière (1999).

${ }^{39}$ En la época de la grabación del disco, el grupo estaba formado por los siguientes músicos: JeanLoup Bonneton (guitarra), Emmanuel Borghi (piano), Eric Prost (saxofón tenor), Gaël Horellou (saxofón alto), David Sauzay (saxofón tenor, saxofón soprano, flauta), Fabien Marcoz (contrabajo), François Gallix (contrabajo), Laurent Sarrien (batería), y Philippe García (batería, percusión).

${ }^{40}$ Casi dos décadas más tarde, concretamente en mayo de 2016, la banda Les Permutants -formada por el contrabajista del grupo Collectiv Mu, François Gallix, y otros ocho músicos- grabó en directo el disco titulado Alive!, que se publicó en 2017; este álbum incluye otra versión del tema Don Quichotte, con una duración de 08:33 minutos. De hecho, Les Permutants es el título de una composición incluida en otro álbum de Collectif $\mathrm{Mu}$, Live au Crescent (1996). Otro tema del álbum Don Quichotte que aparece también en Alive! es la pieza titulada Archie. 
pieza, compuesta e interpretada por los tres integrantes del grupo -Jean-Paul Autin (saxofón alto, saxofón sopranino, clarinete bajo, flauta, banyo), Alfred Spirli (batería, percusión, objetos) y Xavier García (sampler)-, y que tiene una duración de 06:09 minutos, puede ser descrita como una composición que se sitúa entre el jazz experimental y de vanguardia, el free jazz y la música electrónica. Además, según las informaciones incluidas en la contraportada del álbum, el grupo pertenece a la Association à la Recherche d'un Folklore Imaginaire (ARFI), un dato que permite completar la descripción del estilo de su música. El uso de instrumentos tradicionales - como el saxofón alto, el banyo y la batería- en combinación con la técnica del sampling y la improvisación hace de la escucha de las piezas de este disco una experiencia acústica muy original e interesante. El efecto es similar a la banda sonora de una obra cinematográfica, o una obra de teatro radiofónico ${ }^{41}$. El tema Quichotte parece imitar, a lo largo de varios minutos, el galope y el relinchar de Rocinante; sin embargo, uno de los aspectos más destacados de esta pieza es, sin duda, el protagonismo de los diversos efectos sonoros, junto a la ausencia de una melodía, una estructura armónica y un ritmo claramente identificables o reconocibles. En este sentido, cabe señalar el parecido de esta música con los experimentos de Jean Schwarz - a los que nos hemos referido anteriormente en este trabajo- en el ámbito de la música electroacústica y la música concreta.

Otro ejemplo de una grabación de jazz francés inspirada en la novela cervantina es la canción Dona Quixote (Obsession) de Viviane Ginapé, una cantante antillana que ha desarrollado su carrera en Francia. Este tema, que tiene una duración de 07:42 minutos, fue incluido en el álbum en directo titulado Viviane Ginapé invite Mario Canonge - en concert - Obsession (2003) ${ }^{42}$. Se trata de una composición de los brasileños Dori Caymmi y Gilson Peranzzetta (música) con letra original en inglés de Tracy Mann; esta bossa nova se convirtió en una especie de standard de jazz gracias a la interpretación de Sarah Vaughan, quien la incluyó en su álbum Brazilian Romance $(1987)^{43}$. Curiosamente, en lugar de usar el texto original de Tracy Mann -que no tiene nada que ver ni alude en ningún momento a la obra de Cervantes- o una traducción, Viviane Ginapé optó por escribir una letra completamente nueva en francés, una balada que no tiene relación con la versión original inglesa, y cuya característica más sobresaliente es la referencia a Don Quijote. Sin embargo, no alude al Caballero de la Triste Figura tal como lo conocemos, sino que lo sustituye por una protagonista femenina, es decir, por una

\footnotetext{
${ }^{41}$ Las obras de teatro radiofónico reciben también el nombre de radioteatro, radionovela, comedia radiofónica, o audiodrama.

42 Este álbum fue grabado en directo -en la sala La Fenêtre, en París- por los siguientes músicos: Viviane Ginapé (voz), Rubens Santana (bajo), Alain Ginapé (guitarra), Serge Marne (percusión), Jérome Destours (piano), Mario Canonge (piano), Diane Dupuis (voz), y Manu Inacio (voz).

${ }^{43}$ De hecho, la versión de Sarah Vaughan es la primera que se publicó de este tema, que en años posteriores fue grabado también por Dori Caymmi (1988), Kevyn Lettau (1991), Toots Thielemans (1993), Dianne Reeves (2001), Rainforest Trio (2001), Cindy Scott (2009), Linda Briceño (2017) o Cécile McLorin Salvant (2018), entre otros.
} 
«mujer Quijote» ${ }^{44}$. Por lo que se sabe, es la única vez que una versión femenina del mito literario -un «Quijote con faldas»- aparece en el jazz ${ }^{45}$. La interpretación de Viviane Ginapé es agradable y optimista, aunque con un fondo ligeramente melancólico, o quizá romántico; la letra gira en torno a temas como su identidad y su realización como mujer, su preocupación por el paso del tiempo, la importancia de los sueños y las fantasías, el caos de la existencia y el disfrute de la vida, el amor, y el análisis y la aceptación de las obsesiones propias.

El álbum Nocturne (2003) del dúo formado por el guitarrista Patrice Soletti y el clarinetista Aurélien Besnard incluye otra creación jazzística dedicada al héroe cervantino: se trata de la pieza Don Quichotte, un tema instrumental que está dividido en dos partes: Don Quichotte, pt. 1, que tiene una duración de 06:27 minutos, y Don Quichotte, pt. 2, con una duración de 04:57 minutos. La música de Patrice Soletti y Aurélien Besnard en el álbum Nocturne podría ser descrita como música improvisada contemporánea en la que se mezclan influencias de música clásica, electroacústica, rock, jazz experimental y de vanguardia, y free jazz. Una de las características más sobresalientes de estas creaciones musicales es la ausencia de un ritmo y una estructura armónica reconocibles, y el protagonismo de efectos sonoros varios, como ruidos, chirridos, crujidos, golpes, tañidos, etcétera. Es básicamente en los amplios espacios que en esta obra se reservan para la improvisación donde más se nota la influencia jazzística, aunque el disco en su

\footnotetext{
${ }^{44}$ Reproducimos aquí la letra de la canción Dona Quixote (Obsession) de Viviane Ginapé, según aparece en el booklet incluido en la funda del CD: «Ballottée telle un brin de paille dans le vent / En vain, je livre une bataille face au temps / Chevauchant mes rêveries / J'échafaude mes journées la nuit // Brûlées à tous mes feux de paille en volcans / Je vis vertiges et pagailles au dedans / Défiant des moulins avides / Femme « Doña Quichotte » impavide / Dresse des sémaphores inutiles // Je marche à l'envers / Quitte à tout embrasser de travers / La tête en bas d'une spirale / À jamais suspendue / En équilibre intemporel, je jubile / Dans la précarité sur mon fil / Jusqu'à l'expir ! / Aurais-je un jour le temps de vaincre le temps / Oui, je l'avoue, je fais tout à contre temps / Et mes combats juvéniles / N'allument plus mes yeux infantiles // Déboussolée par les aiguilles du temps / Toujours enivrée par le roulis, je tangue / Je vais, je viens et je vire / De ce labyrinthe je veux sortir! / Que dans ma tête se fasse silence! // J'entends la ronde des saisons en confiance / L'insouciance des amants dans la danse / Inexorablement le temps prend son temps / Quand il avance ! // Plus une aiguille / J'arrête et suspends ma séguedille, / Apaise mon souffle exalté / Et savoure à loisir / La fraîcheur animée d'une aube orangée / La chaleur d'une main sur un cil / Je pars tranquille // Revêtue par le vent de fétus de paille / Je veux finir enfin de livrer bataille / J'achève mes insomnies / Libérant mes démons de minuit // Je ne veux plus courir et chasser le vent / Trouver refuge au cœur d'un rêve obsédant / Entre les pages d'un livre / Naviguer de chimères en dérive / Médusée par des mots indicibles // La vie défile / À dire vrai je persiste et jubile / Sifflant une joie retrouvée / Dans ma tonalité / Et funambule intemporelle, je vacille / Jouant de l'équilibre fragile / Pourtant facile !».

${ }^{45}$ Sin embargo, no parece que la letra de Viviane Ginapé esté inspirada -al menos, no de forma directa- en ninguna de las obras literarias cuyas protagonistas son heroínas quijotescas como, por ejemplo, The Female Quixote (1752) de Charlotte Lennox, Female Quixotism (1801) de Tabitha Tenney, Don Quixote: Which Was a Dream (1986) de Kathy Acker, o «Das Werk oder Doña Quichotte» (1989) de Maja Beutler, por citar aquí tan solo algunas obras cuyos títulos aluden directamente a la novela cervantina. Para profundizar en esta materia - de las «mujeres Quijote», o Quijotes femeninos- véanse, por ejemplo, los estudios de Garrigós (2009) o Vilar (2011).
} 
conjunto no pertenece propiamente a este género. Don Quichotte, pt. 1 es un tema con un tono especialmente sombrío, misterioso y dramático; destaca aquí la combinación de los sonidos distorsionados y estridentes de la guitarra eléctrica y los pequeños fragmentos y frases interpretados en el clarinete bajo. En cambio, Don Quichotte, pt. 2 es una pieza mucho más tranquila y bastante más amable: igual que la primera parte, es música atonal, pero en este caso estamos ante una pieza algo más melodiosa, con menos disonancias y chirridos, y una mayor presencia de acordes armoniosos - tocados en la guitarra- y fragmentos melódicos más extensos y más dulces, interpretados en el clarinete. El efecto de esta música, en cualquier caso, es -en ambas partes de este Don Quichotte de Patrice Soletti y Aurélien Besnard- la creación de un ambiente onírico, surrealista, casi fantasmagórico y ligeramente inquietante, como en una alucinación.

En el disco Miniatures (2010) del Olivier Thémines Trio - un grupo de jazz contemporáneo formado por Olivier Thémines (clarinete), Guillaume Hazebrouck (piano), y Kit Le Marec (vibráfono) - encontramos otro tema inspirado en el Quijote, concretamente en la montura del Caballero de la Triste Figura: se trata de una pieza instrumental y relativamente breve -tiene una duración de 03:36 minutoscon el título Rossinante. Al igual que las demás pistas de este álbum, Rossinante es una composición del líder del grupo; en este caso, además, estamos ante una pieza especialmente dulce, delicada y melodiosa, lenta, algo melancólica e incluso onírica -destacan en este sentido los solos del piano (01:24-01:43), el clarinete (01:46:-02:15) y el vibráfono (02:15-02:42)-, con suaves disonancias y un ritmo apacible que parece hacer alusión a los pasos lentos y pausados de Rocinante. El tema, que se podría describir como una fantasía libre sobre Rocinante -sin alusiones directas a la música española ni a la novela cervantina, salvo el título-, parece evocar la melancolía y el cansancio tanto del caballo como del caballero, y un talante que combina cierto aire de tristeza o romántica nostalgia con una actitud de firmeza, serenidad y determinación. El carácter romántico de Rossinante de Olivier Thémines es un rasgo que comparte con otras piezas que hemos mencionado en el presente trabajo, a saber, The Windmills of Your Mind (Les moulins de mon cœur) de Michel Legrand, Barataria de Stéphane Grappelli, Don Quichotte y Don Quichotte $N^{o} 2$ de André Bénichou, Dona Quixote (Obsession) de Viviane Ginapé, y también -aunque en menor medida- Quixote de Okay Temiz y Sylvain Kassap.

Otra pieza instrumental inspirada en la obra cervantina que encontramos en el jazz francés es Don Quichotte, del Doumka Clarinet Ensemble, una composición de Hervé Bouchardy incluida en el álbum Afar (2011). El quinteto formado por Hervé Bouchardy (clarinete, clarinete piccolo, corno di bassetto/clarinete tenor), Alexis Ciesla (clarinete, clarinete bajo), Franck René (clarinete, clarinete bajo), Christophe Gauvert (contrabajo, guitarra) y Christophe Durand (batería, cajón, percusión) es un grupo de jazz contemporáneo y progresivo que amalgama de forma muy original elementos del cool jazz, el post-bop, el jazz postmoderno y el world jazz, la música mediterránea y oriental, y la música clásica europea. El 
tema Don Quichotte del Doumka Clarinet Ensemble tiene una duración de 04:51 minutos; se trata de una pieza elegante, misteriosa y sensual que se caracteriza por un ritmo muy animado y vivaz, en combinación con un tono algo sombrío e inquietante, y una melodía y una estructura armónica que recuerdan a la música española, concretamente el flamenco: en su reseña del álbum Afar, Iván SánchezMoreno (2012) destacaba especialmente los «apuntes ligeramente aflamencados» de esta composición. Además, destaca la presencia de elementos de la música árabe y la tradición balcánica.

En el mismo año de la publicación del álbum Afar del Doumka Clarinet Ensemble, el trompetista Jérôme Etcheberry y su grupo Hoozee Foozee Band estrenan su nuevo disco, titulado Ecce Berry (2011), una obra que se puede describir como jazz clásico, neo-tradicionalista o mainstream, y en la cual destacan las reminiscencias del jazz de Nueva Orléans, el swing clásico y el bebop ${ }^{46}$. Este álbum incluye una pieza inspirada en la novela cervantina, concretamente el tema instrumental Roy de Barataria, que tiene una duración de 04:30 minutos. Roy de Barataria es una composición muy alegre y melodiosa -obra de Jérôme Etcheberry-, con un animado ritmo de swing y, en general, un tono festivo, risueño y optimista. Al igual que en el caso del tema Barataria de Stéphane Grappelli, el título de la pieza hace referencia al episodio de la Ínsula Barataria, en la segunda parte del Quijote de Cervantes (1615), es decir, en los capítulos en los que se cuentan las experiencias de Sancho Panza como gobernador (Cervantes, 1998: II/caps. XXXII, XLII- LIII/889-904, 967-1067) ${ }^{47}$. Concretamente, se trata de un juego de palabras -un recurso que el compositor suele usar, siempre de forma humorística, en los títulos de algunas de sus obras-: el nombre propio Roy, que es bastante común tanto en francés como en inglés, hace pensar en la palabra roi -rey, en español ${ }^{48}$-, y no cabe duda de que una composición jazzística cuyo título hace referencia al Rey de Barataria ha de entenderse como un retrato musical del escudero de Don Quijote. Teniendo en cuenta, además, que estamos ante una pieza particularmente alegre, jovial y agradable, parece que el tema de Jérôme Etcheberry está inspirado, concretamente, en el carácter risueño, vivaracho y hedonista de Sancho Panza, y su forma tan prudente, ecuánime y desenfadada de ejercer el gobierno de su ínsula.

En 2014, el contrabajista francés Pierre Boussaguet y el guitarrista español Carles GR graban juntos el álbum Reflets - Reflejos, que incluye el tema instrumental Don Quichotte, un breve homenaje a la novela cervantina, o a su protagonista, con una duración de 04:02 minutos. En las notas incluidas en el booklet del

\footnotetext{
${ }^{46}$ La grabación del disco fue realizada por Jérôme Etcheberry (trompeta, bugle) y los integrantes de la Hoozee Foozee Band: Pierre Christophe (piano), Raphaël Dever (contrabajo), Mourad Benhammou (batería) y Herbert Jeycemore (trombón); sin embargo, este último no participó en la grabación de Roy de Barataria.

${ }^{47}$ Véase la nota 30 en el presente estudio.

${ }^{48}$ Sin embargo, el origen etimológico del sustantivo roi no está libre de dudas, puesto que podría derivarse también de la voz gaélica antigua ruadh, que significa rojo.
} 
$\mathrm{CD}$, esta pieza, compuesta por Pierre Boussaguet, se define como «vals swing» ${ }^{49}$; además, se podría decir que se trata de una composición de jazz postmoderno, con reminiscencias que abarcan desde la música barroca hasta el swing gitano - gypsy jazz, en inglés, o jazz manouche, en francés- del guitarrista belga Django Reinhardt. Igual que todos los demás temas incluidos en este disco, Don Quichotte es un tema muy melodioso, agradable y relajado. Por lo demás, se podría añadir que esta composición jazzística inspirada en el Quijote transmite una sensación de tranquilidad y serena seriedad, aunque también tiene -igual que algunas otras piezas que hemos mencionado en el presente trabajo- un toque suavemente romántico.

El tema instrumental En avant Sancho! del grupo Les Rugissants es otro ejemplo de una composición del jazz francés inspirada en la novela cervantina, en este caso en el escudero del Caballero de la Triste Figura, Sancho Panza. La pieza, que tiene una duración de 07:14 minutos, se encuentra incluida en el álbum digital L'insecte et la révolution (2014), una obra que se podría describir como jazz postmoderno, post-bop, y jazz contemporáneo de vanguardia, con alguna influencia de la música clásica moderna ${ }^{50}$. El tema En avant Sancho !, compuesto por el pianista Grégoire Letouvet, es una composición muy original, compleja e interesante, que se caracteriza por el juego con suaves disonancias, los amplios espacios para la improvisación, y diversos cambios de ritmo, concretamente la alternancia entre varias partes con el ritmo animado de un vals swingueante, y otras con un ritmo más lento, pausado, flotante, casi en suspenso ${ }^{51}$. El resultado es una pieza muy intensa cuyo temperamento oscila entre lo alegre, impetuoso y efusivo, por un lado, y por otro, lo delicado, onírico, surrealista y romántico.

Otra composición dedicada al personaje del escudero de Don Quijote que encontramos en el jazz francés del siglo XXI es Sancho, del dúo formado por Franck Tortiller (vibráfono, marimba) y François Corneloup (saxofón barítono). Se trata de un tema instrumental, con una duración de 04:45 minutos, incluido en el álbum Singing Fellows (2015), un disco de jazz contemporáneo, postmoderno, experimental y de vanguardia, con influencias que van desde la música clásica moderna hasta la música new age. Sancho es una hermosa y delicada fantasía

\footnotetext{
${ }^{49}$ Esta caracterización se encuentra en una de las reseñas incluidas en el booklet que acompaña el CD Reflets - Reflejos; lleva la firma de Nighthawk, pseudónimo de la periodista y crítica de jazz Claude Rachou, de Toulouse. En su versión original francesa (el citado folleto ofrece también traducciones al español y al inglés), la composición quijotesca de Pierre Boussaguet y Carles GR se describe con las siguientes palabras: «Et puis, enfin la valse swing de Don Quichotte, où l'ombre fugace de Django se promène avec une basse qui brode des arabesques et une guitare qui dessine d'une main légère...» (Nighthawk, 2014).

${ }^{50}$ Este álbum está disponible, por ejemplo, en Spotify, Amazon, y Apple Music.

${ }^{51}$ La banda Les Rugissants está formada por los siguientes músicos: Grégoire Letouvet (piano, piano Rhodes), Rémi Scribe (saxofón soprano, saxofón tenor), Théo Philippe (saxofón alto), Thibaud Merle (saxofón tenor), Corentin Giniaux (clarinete bajo), Raphaël Herlem (saxofón barítono), Léo Jeannet (trompeta, fiscorno), Léo Pellet (trombón), Alexis Coutureau (contrabajo) y Jean-Baptiste Paliès (batería).
} 
compuesta por François Corneloup, una pieza muy elegante, serena y romántica, y que crea un ambiente onírico y ligeramente melancólico ${ }^{52}$. El crítico Philippe Méziat caracterizó esta pieza como «la merveille des merveilles»-«titrée du simple prénom du compagnon du chevalier à la triste figure»- de un álbum que describió como «ce petit bijou de disque» (Méziat, 2016).

Por último, queremos mencionar en nuestra lista de ejemplos la canción Don Quichotte del cantante, batería y compositor Thomy, una pieza con una duración de 06:07 minutos que se encuentra incluida en el álbum digital Thomy - 432 $H Z(2019)^{53}$. Se trata de un disco que se sitúa entre la música pop y el jazz contemporáneo, el jazz latino y el world jazz. El tema Don Quichotte, una composición propia del cantante, es una canción muy animada de jazz vocal contemporáneo, o quizá habría que describirla, con más exactitud, como música pop con influencias del jazz latino y la música soul. Estamos ante un tema ligero, bailable, que cuenta con un estribillo muy sencillo y pegadizo, pero también con partes dedicadas a la improvisación. La letra de la canción -por cierto, muy asequible, y bastante cándida - es una especie de canto espiritual a la vida, al amor, a la felicidad, y al universo como creación divina; en el estribillo, el papel de los músicos y los poetas en este mundo se compara con la empresa de Don Quijote en la novela cervantina: «Pour s'aventurer dans le nouveau monde / Faut se dénuder des fils et être l'onde / L'onde de l'amour / Ronde comme une note / Celle du troubadour qui a joué à Don Quichotte» ${ }^{54}$.

\footnotetext{
52 Ante la ausencia de elementos musicales que permitan una interpretación inequívoca, y la falta de explicaciones en la contraportada o el booklet del CD, se podría poner en duda si esta pieza de Franck Tortiller y François Corneloup está de verdad dedicada al escudero de Don Quijote. Sin embargo, aparte del título, hay otro indicio indirecto que puede servir para apoyar la tesis de que el tema Sancho está inspirado efectivamente en el escudero del Caballero de la Triste Figura, y en la amistad entre ambos personajes: concretamente, el hecho de que al menos otras dos piezas del álbum -concretamente, la primera, Walking fellows, y la última, Valse à deux têtes-, así como el disco en su conjunto -Singing fellows - tienen títulos que parecen aludir a una relación amistosa, o de compañeros, entre dos personas, sugiere que la relación de amistad o de compañerismo es un tema al que los dos músicos franceses han querido dar, de forma consciente, cierta importancia en este disco. Por eso, no parece ser una casualidad que el compositor, François Corneloup, haya optado en el caso de esta pieza por un título que evoca la amistad entre los dos protagonistas de la novela cervantina. Véase también la reseña de Méziat (2016).

53 Thomy es el nombre artístico de Thomy (Thomas) Valdes. El álbum digital Thomy - 432 HZ fue grabado en 2018, pero se publicó al año siguiente en el sello BSM Bio Solar Music; está disponible en portales como Spotify, YouTube, Amazon, etcétera. No nos ha sido posible verificar los nombres de los músicos que participaron en la grabación de este disco, puesto que no aparecen en la portada ni en ninguna de las páginas web que hemos consultado. En los años anteriores, Thomy había actuado acompañado por su banda Thomy \& Co., formada por los siguientes músicos: Thomy (batería, voz), Philippe Valdes (percusión), Alex Iaconno (percusión), Gaby Schenke (saxofón, flauta), Shami Monani (bajo), Stéphane Plottof (teclados) y Marc Foulon (guitarras). Sin embargo, no se ha podido comprobar si son estos los músicos que realizaron la grabación del álbum Thomy $-432 \mathrm{HZ}$.

${ }^{54}$ Reproducimos aquí la letra completa de la canción Don Quichotte de Thomy: «[Estrofa 1:] De Crésus aux clochards bienheureux / On joue tous un rôle merveilleux / Comme le jardinier qui
} 
Como señalamos en el apartado 1 del presente trabajo, en esta investigación nos hemos ocupado del caso de Francia, sin prestar atención específica al jazz de otros países francófonos. Sin embargo, con el fin de completar los datos ofrecidos en este artículo, nos permitimos señalar algunos de los ejemplos más destacados de Canadá y Bélgica: una de las musicalizaciones más importantes de la novela cervantina en el ámbito del jazz es la suite Windmill Tilter: The Story of Don Quixote (1969) del trompetista y compositor canadiense Kenny Wheeler (1930-2014) ${ }^{55}$. En el caso de Canadá, también son interesantes los temas Sancho Suite (1978/1980) del grupo The Bug Alley Band (en los álbumes The Bug Alley Band - Diane Tell, y Bug Alley, respectivamente), Don Quixote (2004) del batería y compositor Vito Rezza (álbum: Drums of Avila), Sancho (2005) del dúo formado por el pianista Miles Black y el bajista Rene Worst (álbum: Two), así como Don Quichotte (2016) de la cantante Janie Renée (álbum: L'Éden est un Bazar). En cuanto al jazz belga, destacamos el tema Les moulins avant (2004) del grupo Traces (álbum: Sigh Moon) ${ }^{56}$.

\section{Conclusión}

En el presente trabajo se han analizado veinte ejemplos de composiciones jazzísticas francesas que están inspiradas o dedicadas al Quijote, o a alguno de los personajes o episodios de esta obra cervantina. Se trata de un número elevado, teniendo en cuenta que, por ejemplo, en el jazz de los países de habla alemana Alemania, Austria, Suiza- se han descrito quince casos, incluyendo versiones de temas creados originalmente por compositores de otros países (Hagedorn, 2019b: 207-209); en España, por citar otro caso, no parece haber apenas composiciones de jazz relacionadas con la novela sobre el Ingenioso Hidalgo. También resulta interesante, en este contexto, el hecho de que el interés por el Quijote, por parte de los compositores y músicos de jazz en Francia, se haya intensificado de tal forma que en las dos primeras décadas del siglo XXI se encuentran tantos ejemplos como en todo el siglo XX. Este incremento puede ser interpretado como un indicio de un interés renovado por la novela cervantina en la música y la cultura galas del

arrose ses plants / On peut tout regarder tendrement // [Estribillo:] Comme un habit de satin / Le monde s'habille d'amour divin / Comme la femme et l'homme s'enlacent / La lune et le soleil dansent dans l'espace / Pour s'aventurer dans le nouveau monde / Faut se dénuder des fils et être l'onde / L'onde de l'amour / Ronde comme une note / Celle du troubadour qui a joué à Don Quichotte / à Don Quichotte // [Estrofa 2:] Comme le sapin qui s'élance au ciel / Nos destins ouvrent grandes leurs ailes / Pour accueillir enfin la vie / Et ne plus être en survie // [Estribillo] // [Estrofa 3:] Les cieux entament une mélodie / Le chant de la grande symphonie / Qui annonce que tout l'univers / Se marie aujourd'hui avec la Terre // [Estribillo]». Queremos expresar nuestro agradecimiento a la profesora Julie Corsin, de la Universidad de Castilla-La Mancha, por la transcripción de la letra de este tema del cantante Thomy.

55 Wheeler era originario de Toronto, pero desarrolló prácticamente toda su carrera en Inglaterra, por lo que su relación con el jazz de la región francófona de Canadá, o con el jazz francés, era escasa.

${ }^{56}$ Para la recepción del Quijote en el jazz suizo véase Hagedorn (2019b). 
siglo XXI, aunque es, sin duda, recomendable valorar estos datos con cautela -al fin y al cabo, en este estudio nos hemos centrado en un ámbito marginal de la escena musical francesa- y ponerlos en contexto, teniendo en cuenta futuros trabajos sobre esta materia.

En las composiciones analizadas en el marco del presente trabajo, la relación con la novela de Cervantes suele establecerse en el título o, en el caso de las canciones, en la letra. Son raros los casos en los cuales esta relación se establece o se expresa, además, por medios musicales: por ejemplo, en la canción The Windmills of Your Mind (Les moulins de mon cour), de Michel Legrand, las formas circulares en la estructura armónica y la melodía evocan el movimiento de las aspas de los molinos de viento. En otros casos encontramos alusiones indirectas a la tierra del Caballero de la Triste Figura, en forma de referencias a la música española: así, el tema Don Quichotte de André Bénichou está inspirado en el Adagio del Concierto de Aranjuez de Joaquín Rodrigo, y la pieza Don Quichotte del Doumka Clarinet Ensemble se caracteriza, entre otros aspectos, por el juego con las referencias al flamenco. Por tanto, se podría concluir diciendo que en la mayoría de los ejemplos que hemos analizado en este estudio, se trata de breves fantasías musicales sobre la novela cervantina o algún aspecto de la misma: fantasías libres en las cuales, salvo excepciones, el vínculo con la obra literaria no se suele establecer ni expresar inequívocamente por medios musicales.

Si, además, miramos con más detalle cuáles son los aspectos del Quijote que más han atraído la atención de los compositores y músicos del jazz francés, resulta evidente que la gran mayoría de los temas del jazz galo que están inspiradas en la obra maestra de Cervantes se centran en el mito literario de Don Quijote, en la figura del protagonista, o en su escudero, Sancho Panza. Concretamente, son trece las composiciones dedicadas al Ingenioso Hidalgo, y hay otras cinco dedicadas a Sancho Panza o al episodio de la Ínsula de Barataria, que es uno de los episodios más estrechamente relacionados con el compañero del Caballero de la Triste Figura; una de ellas -Don Quichotte et Sancho, de Claude Nougaro- trata de ambos personajes. Además, existe una pieza dedicada a Rocinante -Rossinante del Olivier Thémines Trio-, otra que usa la aventura de los molinos de viento como metáfora - The Windmills of Your Mind (Les moulins de mon cour) de Michel Legrand-, y una que emplea como imagen la idea de un Quijote en femenino Dona Quixote (Obsession) de Viviane Ginapé-. Es, sin duda, significativo este interés tan claro por Don Quijote y Sancho Panza, en el jazz francés, sobre todo porque en el jazz de otros países existen también muchos temas inspirados, por ejemplo, en el personaje de Dulcinea (Hagedorn, 2016c); sin embargo, en el jazz galo, y en la música francesa en la que existe alguna influencia jazzística, la única composición dedicada a la dama de los pensamientos de Don Quijote parece ser Dulcinée du Toboso, de la suite Don Quichotte de Jean Schwarz.

En cuanto a la forma de los ejemplos analizados en el presente trabajo, cabe destacar que se trata, en su mayoría, de composiciones de gran complejidad y profundidad; en casi todos los casos estamos ante unos temas de una indiscutible 
calidad compositiva. Bien es cierto que algunos de los temas que hemos examinado en estas páginas se sitúan entre la música pop y el jazz: son piezas que se caracterizan por una estructura algo más sencilla que otras de nuestra lista, en lo que se refiere a la estructura armónica, melódica o rítmica, como, por ejemplo: The Windmills of Your Mind (Les moulins de mon cæur) de Michel Legrand, Barataria de Stéphane Grappelli, Don Quichotte y Don Quichotte $n^{\circ} 2$ de André Bénichou, Don Quichotte et Sancho de Claude Nougaro, o Don Quichotte de Thomy. Pero también en estos casos se puede hablar, por lo general, de una buena calidad en la composición musical, en los arreglos, etcétera. En lo que se refiere a la extensión, la mayoría de las piezas son relativamente breves: una docena tienen una duración de menos de cinco minutos; otras tienen una duración intermedia, de entre cinco y diez minutos. Solo en casos excepcionales, como la suite Don Quichotte de Jean Schwarz -que tiene una duración total de 44:20 minutos- encontramos obras que en el contexto jazzístico podrían ser clasificadas como extensas. En relación con la forma cabe destacar, además, que la gran mayoría de los ejemplos analizados son temas instrumentales: solo hay cuatro canciones con letra -las de Michel Legrand, Claude Nougaro, Viviane Ginapé, y Thomy-, y una pieza instrumental que cuenta con una breve introducción con letra, concretamente la recitación de un fragmento poético de apenas doce segundos (Le chevalier à la triste figure, de Michèle Buirette). Parece evidente, por tanto, que en el jazz francés, el mito de Don Quijote ha inspirado mayoritariamente obras instrumentales de pequeño formato.

Por último, hay que señalar que casi la mitad de las piezas examinadas en el presente trabajo - al menos nueve composiciones, si contabilizamos los dos temas de André Bénichou como uno solo- se caracterizan por un enfoque que podríamos describir como melancólico, introspectivo y romántico; se trata de The Windmills of Your Mind (Les moulins de mon cour) de Michel Legrand, Barataria de Stéphane Grappelli, Don Quichotte y Don Quichotte $N^{o} 2$ de André Bénichou, Quixote de Okay Temiz y Sylvain Kassap, Dona Quixote (Obsession) de Viviane Ginapé, Rossinante de Olivier Thémines, Don Quichotte de Pierre Boussaguet y Carles GR, En avant Sancho! de Les Rugissants, así como Sancho de Franck Tortiller y François Corneloup. Por tanto, se puede afirmar que gran parte de las composiciones dedicadas al Quijote que se encuentran en el jazz francés parecen estar basados -igual que ocurre en el caso del jazz de los países de habla alemana (Hagedorn, 2019b: 209-211) - en la interpretación romántica de la novela, según la cual destacan sobre todo el idealismo y la nobleza del protagonista, el heroísmo de su empresa, y la melancolía de quienes son conscientes de que se trata, desde el principio, de una batalla perdida. Por otra parte, en el gran abanico de enfoques que encontramos en las composiciones examinadas en el presente trabajo, también hay algunas piezas que parecen estar basadas en una perspectiva bien diferente sobre el Quijote. Así, tenemos algunos temas con un tono alegre y optimista, que sin duda están relacionados con la lectura de la novela cervantina como una obra esencialmente cómica; en este sentido, destacan sobre todo las 
piezas Don Quichotte et Sancho de Claude Nougaro, y Roy de Barataria de Jérôme Etcheberry y su Hoozee Foozee Band. Otras composiciones parecen explorar temas como la locura del protagonista -como la suite Don Quichotte de Jean Schwarz, y la composición homónima del grupo Collectif $\mathrm{Mu}-\mathrm{o}$ el carácter fantasmagórico, quimérico o surrealista de sus propósitos, sus ensoñaciones, sus desvaríos y sus acciones - por ejemplo, Le rêve de Don Quichotte de Léon Francioli y Pierre Favre, Le chevalier à la triste figure de Michèle Buirette, o Don Quichotte (pt. 1, pt. 2) de Patrice Soletti y Aurélien Besnard.

Con todo, la presencia tan destacada -y creciente- de Don Quijote en el jazz francés, principalmente en los cincuenta años pasados, y sobre todo en las dos primeras décadas del siglo XXI, puede ser tomada como indicio del enorme interés que este mito literario sigue despertando en la Francia contemporánea, hasta el día de hoy.

\section{REFERENCIAS BIBLIOGRÁFICAS}

ADAM-SCHMIDMEIER, Eva-Maria von (2007): «Tema con variazioni: Don Quijote in der Musik», in Klaus-Dieter Ertler y Sonja Maria Steckbauer (eds.), 400 Jahre Don Quijote. Zur Rezeption des spanischen Klassikers in Europa und in den Amerikas. Fráncfort del Meno, Peter Lang, 17-28.

Alvar, Carlos (dir.) (2005-): Gran Enciclopedia Cervantina. Madrid, Alcalá de Henares, Edhasa, Castalia, Universidad de Alcalá, Centro de Estudios Cervantinos.

Álvarez CALERO, Alberto (2017): «La recepción de El Quijote por compositores y escritores del siglo XVIII en algunos núcleos culturales de Europa». Colindancias. Revista de la Red de Hispanistas de Europa Central, 8, 85-107. URL: https://colindancias.uvt.ro/index.php/colindancias/article/view/195.

BARDON, Maurice (1931): "Don Quichotte" en France au XVII et au XVIII siècle (1605-1815). 2 vols. París, Champion.

BARDON, Maurice (1936): «Don Quichotte et le roman réaliste français : Stendhal, Balzac, Flaubert». Revue de Littérature Comparée, 16, 63-81.

BAUTISTA NARANJO, Esther (2020): El mito de don Quijote en la novela francesa de los siglos XIX y XX. Alcalá de Henares, Instituto Universitario de Investigación "Miguel de Cervantes" de la Universidad de Alcalá.

BENNETT, Marie (2014): «Does the song really remain the same? "The Windmills of Your Mind" as narrational vehicle in The Thomas Crown Affair (1968 and 1999)». The Soundtrack, 7/2, 79-88. URL: https://doi.org/10.1386/st.7.2.79_1.

BERENDT, Joachim-Ernst (1994): El Jazz. De Nueva Orleans al Jazz Rock. México DF, Santafé de Bogotá et al., Fondo de Cultura Económica.

BERENDT, Joachim-Ernst \& Günther HuESMANN (2014): Das Jazzbuch. Von New Orleans bis ins 21. Jahrhundert. Fráncfort del Meno, Fischer.

BERTRAND, Jean-Joseph-Achille (1914): Cervantès et le romantisme allemand. París, Felix Alcan. 
Bravo Castillo, Juan (2007): «Don Quijote como prototipo de la novela europea moderna», in Hans Christian Hagedorn (coord.), Don Quijote por tierras extranjeras. Estudios sobre la recepción internacional de la novela cervantina. Cuenca, Ediciones de la Universidad de Castilla-La Mancha, 31-83.

CAnavaggio, Jean (2005): Don Quichotte : du livre au mythe. Quatre siècles d'errance. París, Fayard.

CDMC - Centre DE DOCUMENTATION DE LA MusiQue CONTEMPORAine (2014): «Schwarz Jean (1939)», in Cdmc - Centre de documentation de la musique contemporaine. URL: http://www.cdmc.asso.fr/en/ressources/compositeurs/biographies/schwarz-jean-1939.

Cervantes, Miguel de (1998): Don Quijote de la Mancha. Edición dirigida por Francisco Rico. Barcelona, Crítica, Instituto Cervantes.

DENIMAL, Guy (2004): «Don Quichotte en musique ou l'utopie source de créativité». Conferencia presentada al «Groupe des Sept» [París, 28/10/2004]. URL: http://donquijotedelamancha.free.fr/DQmusique.pdf.

DuÉE, Claude (2016): «Una transposición de Don Quijote de la Mancha de Cervantes: Don Quichotte dans la Manche de Douay y Leroux», in Hans Christian Hagedorn (coord.), Don Quijote en los cinco continentes. Acerca de la recepción internacional de la novela cervantina. Cuenca, Ediciones de la Universidad de Castilla-La Mancha, 221-260.

ESPINós, Víctor (1947): El "Quijote" en la música. Barcelona, Patronato del IV Centenario del Nacimiento de Cervantes, Consejo Superior de Investigaciones Científicas, Instituto Español de Musicología, Casa Provincial de Caridad. URL: http://www.memoriademadrid.es/buscador.php?accion=VerFicha\&id=229317\&n um_id=2\&num_total=2.

ESQUiVAL-HeINEMANN, Barbara P. (1993): Don Quijote's Sally into the World of Opera. Libretti between 1680 and 1976. Nueva York, Peter Lang.

ETCHARRY, Stéphan (2010): «En torno a la presencia del Quijote en la canción francesa y francófona (1950-2005)», in Begoña Lolo (ed.), Visiones del Quijote en la música del siglo XX. Madrid, Centro de Estudios Cervantinos, 725-744.

ETCHARRY, Stéphan (2017a): «Quichotte, Don», in Carlos Alvar (dir.), Gran Enciclopedia Cervantina. Alcalá de Henares, Instituto Universitario de Investigación "Miguel de Cervantes" de la Universidad de Alcalá, vol. X, 1038410385.

ETCHARRY, Stéphan (2017b): «Quichotte et Sancho, Don», in Carlos Alvar (dir.), Gran Enciclopedia Cervantina. Alcalá de Henares, Instituto Universitario de Investigación "Miguel de Cervantes" de la Universidad de Alcalá, vol. X, 10392.

FlynN, Susan Jane (1984): The Presence of 'Don Quixote' in Music. Tesis doctoral dirigida por A. M. Vazquez-Bigi. Knoxville, The University of Tennessee. URL: http://trace.tennessee.edu/utk_graddiss/2647.

FouCAUlT, Michel (1966): Les mots et les choses. Une archéologie des sciences humaines. París, Éditions Gallimard.

GARRIGÓS, Cristina (2009): «¿Lecturas peligrosas o mujeres alienadas? Quijotismo femenino, locura y metaliteratura», in Hans Christian Hagedorn (coord.), Don 
Quijote, cosmopolita. Nuevos estudios sobre la recepción internacional de la novela cervantina. Cuenca, Ediciones de la Universidad de Castilla-La Mancha, 307-322.

GIORGINI, Massimiliano Adelmo (2015): «Don Quixote in American Song. Underground Hero and Champion of the Counterculture». Cervantes. Bulletin of the Cervantes Society of America, 35:1, 49-76. URL: https://doi.org/10.1353/cer.2015.0000.

GIRARD, René (1961): Mensonge romantique et vérité romanesque. París, Éditions Bernard Grasset.

HAGEDORN, Hans Christian [coord.] (2007): Don Quijote por tierras extranjeras. Estudios sobre la recepción internacional de la novela cervantina. Cuenca, Ediciones de la Universidad de Castilla-La Mancha.

HAGEdoRn, Hans Christian [coord.] (2009): Don Quijote, cosmopolita. Nuevos estudios sobre la recepción internacional de la novela cervantina. Cuenca, Ediciones de la Universidad de Castilla-La Mancha.

HAGEDORN, Hans Christian [coord.] (2016a): Don Quijote en los cinco continentes. Acerca de la recepción internacional de la novela cervantina. Cuenca, Ediciones de la Universidad de Castilla-La Mancha.

HAGEdorn, Hans Christian (2016b): «Don Quijote en el jazz», in Hans Christian Hagedorn (coord.), Don Quijote en los cinco continentes. Acerca de la recepción internacional de la novela cervantina. Cuenca, Ediciones de la Universidad de Castilla-La Mancha, 547-592.

HAGEDORN, Hans Christian (2016c): «Dulcinea Jazz: Don Quixote's Queen and Lady in some Jazz Compositions of the past fifty Years». Literary History (Knjizevna Istorija, The Institute for Literature and Art, Belgrado, Serbia), 48/159, 155-184. URL: http://knjizevnaistorija.rs/editions/159/hagedorn.pdf.

HAGEDORN, Hans Christian (2018): «Sancho Panza en el jazz», in Paloma Ortiz de Urbina (ed.), Cervantes en los siglos XX y XXI. La recepción actual del mito del "Quijote". Berna et al., Peter Lang, 135-151.

HAGEDORN, Hans Christian (2019a): «Don Quijote en el jazz actual (2011-2018)», in Víctor Raúl López Ruiz \& Domingo Nevado Peña (coords.), Congreso Nacional Cervantino - "Querote 2019" - Quero (Toledo). Cuenca, Ediciones de la Universidad de Castilla-La Mancha, 43-55. URL: https://doi.org/10.18239/jor_18.2019.03.

HAGEDORN, Hans Christian (2019b): «Don Quijote en el jazz de los países de habla alemana», in Alfredo Moro Martín (ed.), Cervantes y la posteridad. 400 años de legado cervantino. Madrid - Fráncfort del Meno, Iberoamericana - Vervuert, 193-214.

HAGEDORN, Hans Christian (en prensa): «Los molinos de viento del Quijote en el jazz», in Hans Christian Hagedorn, Silvia Molina Plaza \& Margarita Rigal Aragón (coords.), Literatura, crítica, libertad. Estudios en homenaje a Juan Bravo Castillo. Cuenca, Ediciones de la Universidad de Castilla-La Mancha.

HAGEDORN, Hans Christian (en prensa): «Rocinante a ritmo de jazz», in Francisco Javier Escudero Buendía \& Hans Christian Hagedorn (coords.), Nuevas perspectivas cervantinas: Fuentes, relaciones, recepción. Cuenca, Ediciones de la Universidad 
de Castilla-La Mancha.

HARTAU, Johannes (2007): «Algunas representaciones iconográficas de Don Quijote en Francia». Mélanges de la Casa de Velázquez, 37:2 (Cervantès et la France), 81106. URL: https://doi.org/10.4000/mcv.1692.

Hess, Carol A. (2007): «La presencia de Cervantes en la música estadounidense del siglo XX: recepción y significado», in Begoña Lolo (ed.), Cervantes y el Quijote en la música. Estudios sobre la recepción de un mito. Madrid, Centro de Estudios Cervantinos, 241-252.

Hess, Carol A. (2011): «Música de temática cervantina en el siglo XX - En América del Norte», in Carlos Alvar (dir.), Gran Enciclopedia Cervantina. Madrid, Alcalá de Henares, Edhasa, Castalia, Centro de Estudios Cervantinos, vol. VIII, 8266-8269.

KEIPER, Hugo (2016): “"The Windmills of Your Mind": Notes Towards an Aesthetic of the Pop Song», in Victor Kennedy \& Michelle Gadpaille (eds.), Symphony and Song. The Intersection of Words and Music. Newcastle upon Tyne, Cambridge Scholars Publishing, 15-50.

LABRADOR LÓPEZ DE AZCONA, Germán (2010): «Audiotopías del Quijote en la música rock española (1978-1998). Estrategias de construcción de una identidad», in Begoña Lolo (ed.), Visiones del Quijote en la música del siglo XX. Madrid, Centro de Estudios Cervantinos, 655-682.

LE COLLETER, Thomas (2014): “"Je lui dépêcherais Pança”. Don Quichotte dans la mélodie française: quelques réflexions sur une adaptation (Ravel/Morand/Cervantès)», in Eve Dampierre, Anne-Laure Metzger-Rambach, Vérane Partensky \& Isabelle Poulin (eds.), Traduction et partages : que pensonsnous devoir transmettre? Actes du XXXVII Congrès de la Société Française de Littérature Générale et Comparée. Burdeos, Université Bordeaux-Montaigne, 199-209. URL: http://sflgc.org/acte/thomas-le-colleter-je-lui-depecherais-pancadon-quichotte-dans-la-melodie-francaise-quelques-reflexions-sur-une-adaptationravel-morand-cervantes.

LOLO, Begoña (2006): «El Quijote en la música europea: encuentros y desencuentros». Edad de Oro, 25, 317-332.

LOLO, Begoña [ed.] (2007): Cervantes y el Quijote en la música. Estudios sobre la recepción de un mito. Madrid, Centro de Estudios Cervantinos.

LoLO, Begoña [ed.] (2010): Visiones del Quijote en la música del siglo XX. Madrid, Centro de Estudios Cervantinos.

LOLO, Begoña (2017): «Quichotte et Sancho, Don», in Carlos Alvar (dir.), Gran Enciclopedia Cervantina. Alcalá de Henares, Instituto Universitario de Investigación "Miguel de Cervantes" de la Universidad de Alcalá, vol. X, 10392.

LOLO, Begoña (ed.) (2018): El Quijote y la música en la construcción de la cultura europea. Madrid, Universidad Autónoma de Madrid.

LÓPEZ NAVIA, Santiago Alfonso (2005): «Las recreaciones musicales», in Santiago Alfonso López Navia, Inspiración y pretexto. Estudio sobre las recreaciones del 'Quijote'. Madrid, Fráncfort del Meno, Iberoamericana, Vervuert, 175-203.

LÓPEZ NAVIA, Santiago Alfonso (2010): «La recepción del Quijote en el rock español», in Begoña Lolo (ed.), Visiones del Quijote en la música del siglo XX. Madrid, 
Centro de Estudios Cervantinos, 683-696.

LÓPEZ NAVIA, Santiago Alfonso (2016): «De nuevo sobre la huella del Quijote en la música popular: atención especial a las recreaciones de la música rock», in Carlos Mata Induráin (coord.), Recreaciones quijotescas y cervantinas en las artes. Cervantes y su obra. Pamplona, Ediciones de la Universidad de Navarra, 53-66.

LÓPEZ NAVIA, Santiago Alfonso (2018): «La presencia del Quijote en la música popular española: una breve panorámica», in Carlos Julián Martínez Soria \& Juan Manuel Millán Martínez (coords.), Astrana Marín, Cervantes y Shakespeare. Paralelismos y convergencias. Cuenca, Ediciones de la Universidad de CastillaLa Mancha, 145-160.

MARTÍNEZ DEL FRESNO, Beatriz (2005): «El Quijote en el ballet», in VV.AA., El "Quijote" y la música. Madrid, Instituto Nacional de las Artes Escénicas y de la Música (Centro de Documentación de Música y Danza) del Ministerio de Cultura y Centro Virtual Cervantes. URL: https://cvc.cervantes.es/actcult/quijote_musica/martinez.htm.

MÉZIAT, Philippe (2016): «Franck Tortiller / François Corneloup - Singing Fellows». Citizen Jazz, 10/01/2016. URL: https://www.citizenjazz.com/Franck-TortillerFrancois-Corneloup.html.

MONER, Michel (2004): «La recepción de Don Quijote en Francia». El español en el mundo. Anuario del Instituto Cervantes, 7, 39-56.

MONTERO ReguerA, José (2007): «Un libro, un personaje, un mito». Mélanges de la Casa de Velázquez, 37:2 (Cervantès et la France), 141-148. URL: https://doi.org/10.4000/mcv.1718.

Morton, Brian \& Richard CoOK (2011): The Penguin Jazz Guide. The History of the Music in the 1001 Best Albums. Londres, Nueva York et al., Penguin.

NighthawK (RACHOU, Claude) (2014): «[sin título; notas incluidas en el booklet del álbum Reflets - Reflejos, de Pierre Boussaguet y Carles GR]», in Pierre Boussaguet y Carles GR, Reflets - Reflejos. [CD]. Barcelona, Swit Records.

NOMMICK, Yvan (2007): «El Quijote en la música del siglo XX: metamorfosis, fantasías y nuevas visiones», in Begoña Lolo (ed.), Cervantes y el Quijote en la música. Estudios sobre la recepción de un mito. Madrid, Centro de Estudios Cervantinos, 209-240.

NOMMICK, Yvan (2010): «Visiones de España en la música francesa del siglo XX de inspiración quijotesca», in Begoña Lolo (ed.), Visiones del Quijote en la música del siglo XX. Madrid, Centro de Estudios Cervantinos, 337-356.

NORDIN, Ingvar Loco (sin año): «Gamma Plus! - Jean Schwarz - Gamma Plus», in Sonoloco Record Reviews. URL: http://www.sonoloco.com/rev/grm/e5006/schwarz.html.

OrTIZ-DE-URbina SobrinO, Paloma (2019): «El mundo mítico de la "Cueva de Montesinos" en la música para Don Quixote de Roberto Gerhard». Anales Cervantinos, 51, 125-146. URL: https://doi.org/10.3989/anacervantinos.2019.006.

Padilla Alonso, Elena, Benita PÉrez CAlvo \& Julio Alejandro Villalmanzo SANTAMARÍA (2016): «Los otros recorridos de El Quijote». Biblioteca: Estudio e 
Investigación, 31 (número dedicado a: Paz y bien [Las órdenes mendicantes en la Ribera del Duero]), 393-419.

PASTOR COMín, Juan José (2010): «Del Quichotte de Jacques Ibert a la escritura última de Maurice Ravel: Música para Cervantes, Prélude de mort». Anuario de Estudios Cervantinos, 6 (Eduardo Urbina, Jesús G. Maestro, eds., Crítica, ecdótica y poética del "Quijote”), 187-211.

PEYRÈGNE, Françoise (2003): «La figure de don Quichotte dans la production musicale du XX ${ }^{\mathrm{e}}$ siècle», in Danielle Perrot (ed.), Don Quichotte au XXe siècle. Réceptions d'une figure mythique dans la littérature et les arts. Clermont-Ferrand, Centre de Recherches sur les Littératures Modernes et Contemporaines, Presses Universitaires Blaise Pascal, 63-78.

Pujante Cascales, Basilio (2010): «Don Quijote en el rock español: el caso de $L a$ leyenda de la Mancha de Mägo de Oz», in Begoña Lolo (ed.), Visiones del Quijote en la música del siglo XX. Madrid, Centro de Estudios Cervantinos, 697708.

Querol GavaldA, Miguel (2005): «Cervantes en las obras de música», in Miguel Querol Gavalda, La música en la obra de Cervantes. Alcalá de Henares, Centro de Estudios Cervantinos, 203-212 [publicado originalmente en 1948].

ROBERT, Marthe (1972): Roman des origines et origines du roman. París, Éditions Bernard Grasset.

SÁNCHEZ-MORENO, Iván (2012): «Afar - Doumka Clarinet Ensemble». B!ritmos, 14 de febrero. URL: http://www.b-ritmos.com/doumka-clarinet-ensemble.

SANZ MANZANO, María Ángeles \& Joaquín RuBio TovaR (2011): «Catálogo general», «Cronológico», «Por nacionalidades» («Música»), in Carlos Alvar (dir.), Gran Enciclopedia Cervantina. Madrid, Alcalá de Henares, Edhasa, Castalia, Centro de Estudios Cervantinos, vol. VIII, 8271-8377 [para el apartado correspondiente a «Francia»: 8364-8368].

SCHWARZ, Jean (1981): «Don Quichotte», in Jean Schwarz, Don Quichotte. [Disco de vinilo; texto incluido en la contraportada de la funda del disco]. Viroflay, Celia Records.

VAN HALEN, Edit (2016): «Jean Schwarz - Don Quichotte», in Edit Van Halen, Wave Edge - A Collection of Antiques and Curios, 2 de junio. URL: http://waveedge.blogspot.com/2016/06/jean-schwarz-don-quichotte.html?m=1.

VILAR, Loreto (2011): «De la lucha de una mujer contra molinos de viento, o: Doña Quijote en Suiza según Maja Beutler», in Hans Christian Hagedorn (coord.), Don Quijote en su periplo universal. Aspectos de la recepción internacional de la novela cervantina. Cuenca, Ediciones de la Universidad de Castilla-La Mancha, 89-111.

VV.AA. (2005): El "Quijote" y la música. Madrid, Instituto Nacional de las Artes Escénicas y de la Música (Centro de Documentación de Música y Danza) del Ministerio de Cultura y Centro Virtual Cervantes. URL: https://cvc.cervantes.es/actcult/quijote_musica/default.htm.

WEBER, Eckhard (2005): «Don Quijote en la historia de la música», in Carlos Mata Induráin \& Miguel Zugasti (coords.), Actas del Congreso "El Siglo de Oro en el 
Nuevo Milenio”. Pamplona, Ediciones de la Universidad de Navarra, vol. 2, 1743-1756.

YlleRA, Alicia (2008): «Francia», in Carlos Alvar (dir.), Gran Enciclopedia Cervantina. Madrid, Alcalá de Henares, Castalia, Centro de Estudios Cervantinos, vol. V, 4934-4960.

ANEXO

Tabla $\mathrm{n}^{\circ}$ 1. Listado de ejemplos

\begin{tabular}{|c|c|c|c|}
\hline $\begin{array}{l}\text { COMPOSITOR, } \\
\text { MÚSICO O GRUPO }\end{array}$ & $\begin{array}{l}\text { COMPOSICIÓN } \\
\text { (TEMA U OBRA) }\end{array}$ & ÁLBUM & AÑNO \\
\hline Jean Rivier & $\begin{array}{l}\text { Ouverture pour un Don } \\
\text { Quichotte }\end{array}$ & - & 1929 \\
\hline Michel Legrand & $\begin{array}{l}\text { The Windmills of Your Mind } \\
\text { (Les moulins de mon coeur) }\end{array}$ & $\begin{array}{l}\text { [sencillo: The Windmills } \\
\text { of Your Mind, cantante: } \\
\text { Noel Harrison] }\end{array}$ & 1968 \\
\hline Jean Schwarz & Don Quichotte & Don Quichotte & $\begin{array}{l}1975- \\
1976 \\
(1981)\end{array}$ \\
\hline $\begin{array}{l}\text { Léon Francioli, } \\
\text { Pierre Favre }\end{array}$ & Le rêve de Don Quichotte & Le bruit court... & 1976 \\
\hline Stéphane Grappelli & Barataria & + Cordes & 1978 \\
\hline André Bénichou & $\begin{array}{l}\text { Don Quichotte, } \\
\text { Don Quichotte n } 2\end{array}$ & Adagissimo & 1981 \\
\hline Michèle Buirette & Le chevalier à la triste figure & La mise en plis & 1985 \\
\hline $\begin{array}{l}\text { Okay Temiz, } \\
\text { Sylvain Kassap }\end{array}$ & Quixote & Istanbul' da Eylül & 1990 \\
\hline Claude Nougaro & Don Quichotte et Sancho & L'Enfant phare & 1997 \\
\hline Collectif Mu & Don Quichotte & Don Quichotte & 1997 \\
\hline L'Effet Vapeur & Quichotte & $\begin{array}{l}\text { En concert-Je pense } \\
\text { que... }\end{array}$ & 2002 \\
\hline Viviane Ginapé & Dona Quixote (Obsession) & $\begin{array}{l}\text { Viviane Ginapé invite } \\
\text { Mario Canonge - en con- } \\
\text { cert-Obsession }\end{array}$ & 2003 \\
\hline $\begin{array}{l}\text { Patrice Soletti, } \\
\text { Aurélien Besnard }\end{array}$ & Don Quichotte (pt. 1, pt. 2) & Nocturne & 2003 \\
\hline Olivier Thémines Trio & Rossinante & Miniatures & 2010 \\
\hline $\begin{array}{l}\text { Doumka Clarinet Ense- } \\
\text { mble }\end{array}$ & Don Quichotte & Afar & 2011 \\
\hline Jérôme Etcheberry, & Roy de Barataria & Ecce Berry & 2011 \\
\hline
\end{tabular}




\begin{tabular}{|l|l|l|c|}
\hline $\begin{array}{c}\text { COMPOSITOR, } \\
\text { MÚSICO O GRUPO }\end{array}$ & \multicolumn{1}{|c|}{$\begin{array}{c}\text { COMPOSICIÓN } \\
\text { (TEMA U OBRA) }\end{array}$} & ÁLBUM & AÑO \\
\hline Hoozee Foozee Band & & Reflets - Reflejos & 2014 \\
\hline $\begin{array}{l}\text { Pierre Boussaguet, Car- } \\
\text { les GR }\end{array}$ & Don Quichotte & L'insecte et la révolution & 2014 \\
\hline Les Rugissants & En avant Sancho! & Singing Fellows & 2015 \\
\hline $\begin{array}{l}\text { Franck Tortiller, } \\
\text { François Corneloup }\end{array}$ & Sancho & Thomy $-432 \mathrm{HZ}$ & 2019 \\
\hline Thomy & Don Quichotte & & \\
\hline
\end{tabular}

